\title{
Chad Centner
}

Division of Medical Microbiology

Department of Pathology

University of Cape Town

\section{Master of Medicine Part III}

(minor dissertation in published paper format)

\section{Evolution of sensory neuropathy after initiation of antiretroviral therapy}

\author{
Supervisor: \\ Prof Jeannine Heckmann \\ Division of Neurology \\ Department of Medicine \\ University of Cape Town
}

14 June 2018 
The copyright of this thesis vests in the author. No quotation from it or information derived from it is to be published without full acknowledgement of the source. The thesis is to be used for private study or noncommercial research purposes only.

Published by the University of Cape Town (UCT) in terms of the non-exclusive license granted to UCT by the author. 


\section{$\underline{\text { Table of contents }}$}
1) Declaration
2) Abstract
3) Acknowledgements and contributions
4) List of tables
5) List of figures
6) Abbreviations
7) Minor dissertation in published paper format (Muscle \& Nerve)
8) Supplementary material (Muscle \& Nerve)
9) Reviewers' comments and responses (Muscle \& Nerve)
10) Editorial and issue highlights (Muscle \& Nerve)
11) Data capture instruments
12) Consent form and participant information sheet
13) Ethics approval
14) Instructions to authors (Muscle \& Nerve) 


\section{1) Declaration}

The research reported here is based on independent work performed by myself and co-authors (see (3) Acknowledgements and contributions) and neither the whole work nor part of it has been, is being, or is to be submitted for another degree to any other university. The work was not reported or published prior to registration for the Master of Medicine degree.

\section{Signed by candidate}

Chad Centner

14 June 2018 


\section{2) Abstract}

Introduction: We studied the evolution of sensory neuropathy after antiretroviral therapy (ART) in human immunodeficiency virus-infected South Africans.

Methods: Enrolment commenced before ART with 6-monthly follow-ups for 24 months. Symptomatic distal sensory polyneuropathy (SDSP) was defined as one symptom and sign. Symptom/sign scores were compared between visits.

Results: We enrolled 184 participants. Pre-ART, 16\% had SDSP. After 18 months of ART, pain prevalence decreased in those with pre-ART SDSP (odds ratio [OR], 0.09; 95\% confidence interval [95\%Cl], 0.03-0.29). Symptoms improved in 50\% ever experiencing pain (mean improvement=-4.5 on 11-point scale). Participants SDSP-free pre-ART developed SDSP at a rate of 18 per 100 personyears. After 24 months, $18 \%$ had SDSP. Stavudine (60\% of cohort) did not predict incident SDSP, but associated with increased prevalence of reduced/absent reflexes at 18 months $(\mathrm{OR}, 2.24 ; 95 \% \mathrm{CI}$, 1.08-4.65).

Conclusions: Painful symptoms improved during ART. Evolving sensory neuropathy was due to increasing small and large fiber dysfunction. 


\section{3) Acknowledgements and contributions}

\section{Chad Centner:}

- Participant recruitment

- Participant assessment and data collection

- Data collation and database clean-up

- Statistical analysis

- Descriptive statistics, comparative statistics, survival analysis, longitudinal modelling

- Write-up of manuscript as first author

- Submission of manuscript to Muscle \& Nerve

- Response to reviewers

- Review of final manuscript

\section{Francesca Little:}

- Statistical analysis, support and supervision - Survival analysis, longitudinal modelling

- Review of final manuscript

Johan van der Watt:

- Participant recruitment

- Participant assessment and data collection

- Contribution to manuscript write-up

- Review of final manuscript

John-Randel Vermaak:

- Participant recruitment

- Participant assessment and data collection

- Review of final manuscript

Joel Dave:

- Metabolic data collection and analysis

- Review of final manuscript

\section{Naomi Levitt:}

- Metabolic data collection and analysis

- Review of final manuscript

Jeannine Heckmann:

- Principal investigator

- MMed supervisor

- Study design

- Participant assessment and data collection

- Write-up of manuscript as senior author

- Submission of manuscript to Muscle \& Nerve

- Response to reviewers

- Review of final manuscript

I wish to thank Sr. Carmen Delport, Chantal Stuart, Malibongwe Majola, Nick Faunce, and the staff at Crossroads Community Health Centre, Cape Town. 


\section{4) List of tables}

Table 1. Baseline (pre-antiretroviral therapy) and 24-month clinical and laboratory characteristics by symptomatic distal sensory polyneuropathy status

Table 2. Evolution of neuropathic symptoms and signs between first occurrence of abnormality to last follow-up

Table 3. Comparison of symptom and sign prevalence (odds ratios) between baseline (preantiretroviral therapy) and follow-up visits

Supplementary Table 1. Additional baseline (pre-antiretroviral therapy) and 24-month clinical and laboratory characteristics by symptomatic distal sensory polyneuropathy status

Supplementary Table 2. Distribution of baseline (pre-antiretroviral therapy) symptom scores (numerical rating scale) and sign scores

Supplementary Table 3. Comparison of symptom and sign prevalence (odds ratios) between baseline and follow-up visits by baseline symptomatic distal sensory polyneuropathy (SDSP) status (baseline SDSP vs. no baseline SDSP), and comparison between the two groups at each visit

Supplementary Table 4. Comparison of symptom and sign prevalence (odds ratios, and $95 \%$ confidence intervals) between baseline and follow-up visits by stavudine regimen (participants receiving stavudine vs. not receiving stavudine), and comparison between the two groups at each visit 


\section{5) List of figures}

Figure 1. Modelled prevalence of neuropathic symptoms and signs at each visit over 18 months

Figure 2. Modelled prevalence of neuropathic symptoms and signs at each visit over 18 months in and between groups

Supplementary Figure 1. Symptoms and signs at each visit in the group that entered the study with baseline (pre-antiretroviral therapy) asymptomatic distal sensory polyneuropathy vs. group that entered the study free of sensory neuropathy 


\section{6) Abbreviations}

ADSP $=$ asymptomatic distal sensory polyneuropathy

ART $=$ antiretroviral therapy

BPNS= brief peripheral neuropathy screen

$\mathbf{C l}=$ confidence interval

HIV = human immunodeficiency virus

$\mathbf{H R}=$ hazard ratio

IQR= interquartile range

NRS $=$ numerical rating scale

OR= odds ratio

SDSP = symptomatic distal sensory polyneuropathy

SEM $=$ standard error of the mean

TB $=$ tuberculosis

$\mathrm{TNSr}=$ reduced total neuropathy score 
7) Minor dissertation in published paper format (Muscle \& Nerve) 


\title{
EVOLUTION OF SENSORY NEUROPATHY AFTER INITIATION OF ANTIRETROVIRAL THERAPY
}

\author{
CHAD M. CENTNER, MSc, ${ }^{1}$ FRANCESCA LITTLE, PhD, ${ }^{2}$ JOHAN J. VAN DER WATT, PhD, ${ }^{1}$ JOHN-RANDEL VERMAAK, MSc, ${ }^{1}$ \\ JOEL A. DAVE, PhD, ${ }^{3}$ NAOMI S. LEVITT, MBChB ${ }^{3}$ and JEANNINE M. HECKMANN, PhD ${ }^{1,4}$ \\ ${ }^{1}$ Neurology Research Group, Department of Medicine, University of Cape Town, South Africa \\ ${ }^{2}$ Department of Statistical Sciences, University of Cape Town, South Africa \\ ${ }^{3}$ Division of Endocrinology \& Diabetic Medicine, Department of Medicine, University of Cape Town, South Africa \\ ${ }^{4}$ E8-74, Division of Neurology, Department of Medicine, Groote Schuur Hospital and University of Cape Town, Cape Town, 7925, \\ South Africa \\ Accepted 27 May 2017
}

ABSTRACT: Introduction: We studied the evolution of sensory neuropathy after antiretroviral therapy (ART) in human immunodeficiency virus-infected South Africans. Methods: Enrolment commenced before ART with 6-monthly follow-ups for 24 months. Symptomatic distal sensory polyneuropathy (SDSP) was defined as one symptom and sign. Symptom/sign scores were compared between visits. Results: We enrolled 184 participants. Pre-ART, $16 \%$ had SDSP. After 18 months of ART, pain prevalence decreased in those with pre-ART SDSP (odds ratio [OR], 0.09; 95\% confidence interval [95\%Cl], 0.030.29). Symptoms improved in $50 \%$ ever experiencing pain (mean improvement $=4.5$ on 11-point scale). Participants SDSP-free pre-ART developed SDSP at a rate of 18 per 100 person-years. After 24 months $(n=102), 18 \%$ had SDSP. Stavudine ( $60 \%$ of cohort) did not predict incident SDSP, but associated with increased prevalence of reduced/absent reflexes at 18 months (OR, 2.24; 95\% Cl, 1.08-4.65). Discussion: Painful symptoms improved during ART. Evolving sensory neuropathy was due to increasing small and large fiber dysfunction. Muscle Nerve 57: 371-379, 2018

Sensory neuropathy, comprising painful symptomatic distal sensory polyneuropathy (SDSP) and asymptomatic distal sensory polyneuropathy (ADSP), is a frequent manifestation of human immunodeficiency virus (HIV) infection. Sensory neuropathy has a multifactorial pathogenesis, affecting both small and large sensory fibers. ${ }^{1,2}$ SDSP manifests as distal lengthdependent and symmetrical neuropathic symptoms of numbness, paresthesia, and/or burning pain. Painful SDSP is noted in patients with advanced HIV

Additional supporting information may be found in the online version of this article

Abbreviations: ADSP, asymptomatic distal sensory polyneuropathy; ART, antiretroviral therapy; BPNS, brief peripheral neuropathy screen; $\mathrm{Cl}$, confidence interval; HIV, human immunodeficiency virus; HR, hazard ratio; IQR, interquartile range; NRS, numerical rating scale; OR, odds ratio; SDSP, symptomatic distal sensory polyneuropathy; TB, tuberculosis; TNSr, reduced total neuropathy score

Key words: HIV; neuropathic pain; peripheral neuropathy; sensory neuropathy; sub-Saharan Africa

Funding: This work was supported by: the University of Cape Town Neurology Fund (J.-R.V., C.M.C.); the Duncan-Baxter Scholarship (C.M.C.); the Clinical Infectious Disease Research Initiative, University of Cape Town, Cape Town, South Africa (Wellcome Trust, London, UK; J.J.v.d.W. 084323); Carnegie Corporation, New York, NY, USA (J.J.v.d.W.).

Conflicts of Interest: The authors have no conflicts of interest to declare.

Correspondence to: J. M. Heckmann; e-mail: jeanine.heckmann@uct. ac.za

(C) 2017 Wiley Periodicals, Inc.

Published online 31 May 2017 in Wiley Online Library (wileyonlinelibrary.com). DOI 10.1002/mus.25710 infection, or coincident with symptoms of concomitant tuberculosis (TB) infection, either before or more commonly soon after initiation of $\mathrm{TB}$ treatment, ${ }^{3}$ or within the first $3-6$ months of antiretroviral therapy (ART). Incident SDSP within the first 6 months of ART occurs particularly in those treated with dideoxynucleotide reverse transcriptase inhibitors (e.g., stavudine) and/or with a greater CD4 + cell recovery. ${ }^{4-7}$ While ADSP is prevalent among individuals before starting ART, the prevalence of ADSP increases over time post-ART initiation. ${ }^{8,9}$

Research has focused on identifying factors that predict sensory neuropathy risk; however, fewer studies have prospectively and longitudinally followed patients from before initiation of ART. Therefore, the evolution and recovery of established neuropathic symptoms and signs during ART is not well described. Evans et al. (2011) followed a study cohort prospectively but these participants entered the study at varied times after starting ART. ${ }^{8}$ Another prospective cohort from sub-Saharan Africa followed participants for 6 months after ART initiation and reported the resolution of neuropathic symptoms in $22 \%$ and signs in $23 \% .^{10}$

This study describes the evolution of sensory neuropathy during the first 2 years of ART in a community-based cohort of black South Africans enrolled in a government-run HIV treatment program. We focused on the response of pre-existing HIV-associated SDSP to ART initiation, the incidence of SDSP after ART initiation, comparing stavudine versus non-stavudine-containing regimens and other risk factors, and the temporal evolution of sensory symptoms and signs.

\section{PATIENTS AND METHODS}

Study Design, Setting, and Population. Over a 1.5-year period HIV-infected patients scheduled to commence ART within the following 7 days were recruited from the HIV clinic at Crossroads Community Health Centre in Cape Town, South Africa. Patients attend this clinic on an outpatient basis and are, therefore, generally medically stable. The primary demographic is black, predominantly Xhosaspeaking South Africans.

Participants were eligible if $\geq 18$ years, had confirmed HIV infection, and met criteria for ART initiation in the 
government-run HIV treatment program (before May 2010: CD4 + cell count $\leq 200$; after May 2010: CD4 + cell count $\leq 350$ cells $/ \mathrm{mm}^{3}$ ). Study entry exclusion criteria were known diabetes mellitus, serious systemic illness, severe diarrhea, comorbid neurological disease, TB treatment initiated within the preceding 2 months, exposure to glucocorticoids within the preceding 6 months, and pregnancy.

The University of Cape Town Research Ethics Committee approved this prospective longitudinal cohort study. Participants provided written informed consent to participate.

Participant Assessment. Participants were examined before the initiation of ART (referred to as baseline), and 3, 6, 12, 18 and 24 months thereafter, or until loss to follow-up. At each visit, participants underwent a basic examination including resting blood pressure, focused neuropathy examination, anthropometrical assessments, and metabolic analyses (fasting glucose, insulin, cholesterol, triglycerides, low density lipoprotein, and high density lipoprotein). Clinical, medication, and alcohol use history and other laboratory data were obtained from chart review and participant interview. Alcohol use was defined as any alcohol intake during the previous year. ${ }^{2}$ Laboratory data obtained from chart review consisted of baseline creatinine, alanine transferase, hemoglobin, white cell count, baseline/pre-ART and 24-week CD4 + cell count, and 24-week viral load (baseline viral loads were not routinely performed in South African government-run HIV programs).

The focused neuropathy examination was performed by one of four clinicians (C.M.C., J.J.v.d.W., J.-R.V., and J.M.H.) using the Brief Peripheral Neuropathy Screen (BPNS) ${ }^{11}$ and a reduced version of the Total Neuropathy Score (TNSr) as previously described. ${ }^{2}$ Worst pain, paresthesia, and numbness symptom severity were subjectively assessed on a visual numerical rating scale (NRS) from 0 to 10 using a Xhosa-translated symptom questionnaire as part of the BPNS tool. ${ }^{2}$ The anatomical extent of symptoms (any of pain, paresthesia, or numbness) were also scored according to the TNSr and included no abnormality (0), involvement of the toes and/or soles of feet only (1), extending to the ankles (2), knees (3), and extending above the knees and/or including hands (4). The neuropathy examination included assessments of vibratory and pinprick sensation, and tendon reflexes as part of the BPNS and TNSr. The anatomical extent of vibration and pinprick sensation impairment was scored from 0 to 4 according to the TNSr as for symptoms above. Reflexes were scored as normal (0), reduced ankle jerks (1), absent ankle jerks (2), absent ankle jerks and others reduced (3), and all reflexes absent (4). In addition, position sensation was evaluated at the big toe and abnormal position sensation defined as $>20 \%$ mistakes (out of 10 trials). All abnormal scores required bilateral symmetrical involvement.

Definitions. The diagnosis of SDSP required the presence of $\geq 1$ sensory symptom (pain, paresthesia or numbness) with $\geq 1$ neuropathic sign (impaired vibration sensation, impaired pinprick sensation, or reduced/absent reflexes). ADSP was defined by the presence of $\geq 1$ neuropathic sign in the absence of sensory symptoms. Incident SDSP was defined as no symptoms at baseline with development of SDSP after ART initiation. Worsening symptoms were denoted by at least 2-point increase in NRS, whereas improvement was denoted by at least 2-point decrease in NRS. ${ }^{12}$ At least 1-point change in TNSr denoted either worsening or improvement of sensory symptoms and neuropathic signs.

Statistical Analysis. Stata 12.0 (StataCorp. College Station, Texas) was used for the statistical analysis. The participant characteristics and neuropathy scores at baseline (preART) and at 24 months were described by proportions or medians with interquartile range (IQR). Differences between the SDSP group and SDSP-free group were compared using the chi-square test and Wilcoxon rank-sum test. Multiple logistic regression predicted baseline SDSP in a model that included the significant risk factors $(P<0.05)$ of participant age (per unit increase), previous/current TB, waist:hip ratio (per 0.01 unit increase), and triglyceride levels (per 0.1 unit increase). An odds ratio (OR) and 95\% confidence interval (CI) was estimated for each covariate.

A multivariate Cox-proportional hazards regression model was used to predict onset of incident SDSP in participants who were SDSP-free at baseline, and used age $\geq 40$ and fasting insulin as covariates. Data were assumed to be uninformatively censored. The hazard ratio (HR) and 95\% CI are presented. The magnitude of symptom NRS and TNSr improvement/worsening over time was estimated by the mean score difference (with standard errors) between 2 visits (from the first observation of the abnormality until the last observation) for each symptom and sign in all participants ever experiencing the abnormality.

Population average logistic regression models, assuming an exchangeable within-subject correlation structure, were used to model the prevalence of symptoms and signs at each visit. Prevalence was compared with baseline in the whole cohort, and then in and between groups. Model A compared the group that entered the study with SDSP versus the group that entered the study SDSP-free; and Model $\mathrm{B}$ compared the group that received a stavudine-containing regimen versus a non-stavudine-containing regimen. As a result of nonmonotonic nonlinear time profiles, time was treated as a categorical variable and modeled as a dummy variable that compared prevalence at follow-up visits to that at baseline. The model was plotted and estimated ORs and 95\% CIs reported. Because of missing data, the 24-month visit was excluded from the analysis and models were repeated on imputed data; results for the analysis done on the imputed data supported the analysis done on the unimputed data.

\section{RESULTS}

Baseline Characteristics. One hundred and ninety patients were enrolled in the study. Two participants were excluded as they did not commence ART within 2 weeks of the baseline (pre-ART) assessment. One participant was excluded because of asymmetrical neuropathic signs on examination and three withdrew consent. The baseline study sample, therefore, comprised 184 participants.

The baseline assessment was performed a median of 1 day before initiation of ART (IQR 15). The study population was predominantly women $(70 \%)$, with a median age of 33 years (Table 1, Supplementary Table S1, which is available online). Overall, $38 \%$ had a history of previous or current TB treatment; $57 \%$ of this group had completed TB treatment before study entry, 
Table 1. Baseline (pre-antiretroviral therapy) and 24-month clinical and laboratory characteristics by SDSP status.

\begin{tabular}{|c|c|c|c|c|c|c|c|c|}
\hline \multirow[b]{2}{*}{ Characteristic } & \multicolumn{4}{|c|}{ Baseline } & \multicolumn{4}{|c|}{ 24-month } \\
\hline & Total $n=184$ & $\operatorname{SDSP} n=30$ & SDSP-free $n=154$ & $P$-Value & Total $n=102$ & $\operatorname{SDSP} n=18$ & SDSP-free $n=84$ & $P$-Value \\
\hline Women, $n$ (\%) & $130(70.3)$ & $20(66.7)$ & $110(71.0)$ & 0.64 & 72 (70.6) & $11(61.1)$ & $61(72.6)$ & 0.33 \\
\hline Age, ${ }^{\ddagger}$ years & $33(26-39)$ & $37(26-44)$ & $32(26-37)$ & 0.013 & $35(29-42)$ & $39.5(32-47)$ & $33.5(28.5-39.5)$ & 0.030 \\
\hline Height $^{\ddagger}, \mathrm{cm}$ & $161(156-167)$ & $162(155-168)$ & $161(156-167)$ & 0.64 & $161(156-167)$ & $162(155-168)$ & $161(156-167)$ & 0.67 \\
\hline Body mass index, ${ }^{\ddagger} \mathrm{kg} / \mathrm{m}^{2}$ & $23.3(20.4-27.7)$ & $23.7(21.0-25.9)$ & $23.2(20.4-27.8)$ & 0.60 & $26.7(21.7-32.7)$ & $25.6(21.5-32.0)$ & $26.7(21.9-32.7)$ & 0.85 \\
\hline Waist:hip ratio ${ }^{\ddagger}$ & $0.86(0.81-0.90)$ & $0.88(0.84-0.93)$ & $0.85(0.81-0.90)$ & 0.010 & $0.86(0.82-0.92)$ & $0.90(0.85-0.94)$ & $0.86(0.81-0.90)$ & 0.10 \\
\hline Previous TB, $n(\%)$ & $69(37.3)$ & $51(73.9)$ & $51(32.9)$ & 0.005 & $39(38.6)$ & $7(38.9)$ & $32(38.6)$ & 0.98 \\
\hline Current TB, $n(\%)$ & $29(15.7)$ & $9(30.0)$ & 20 (12.9) & 0.018 & $0(0)$ & $0(0)$ & $0(0)$ & \\
\hline Alcohol use, $n(\%)$ & $51(28.7)$ & $6(20.7)$ & $45(30.2)$ & 0.30 & ND & & & \\
\hline CD4 + count, ${ }^{\ddagger}$ cells $/ \mathrm{mm}^{3}$ & $156(113-195)$ & $156(105-217)$ & $157(114-194)$ & 0.56 & ND & & & \\
\hline CD4 + count $\leq 200, n(\%)$ & $138(77.1)$ & $21(72.4)$ & 117 (78.0) & 0.51 & ND & & & \\
\hline Fasting glucose, ${ }^{\ddagger} \mathrm{mmol} / \mathrm{L}$ & $4.7(4.4-4.9)$ & $4.7(4.5-4.9)$ & $4.6(4.4-4.9)$ & 0.56 & $4.7(4.4-5.0)$ & $4.6(4.3-5.2)$ & $4.7(4.4-5.0)$ & 0.98 \\
\hline OGT $(120 \mathrm{~min}),{ }^{\ddagger} \mathrm{mmol} / \mathrm{L}$ & $5.3(4.6-6.1)$ & $5.5(4.6-6.7)$ & $5.2(4.6-6.1)$ & 0.17 & $5.2(4.4-5.9)$ & $5.5(5.1-6.7)$ & $5.0(4.3-5.7)$ & 0.004 \\
\hline Impaired OGT, $n$ (\%) & $15(9.1)$ & $3(11.1)$ & $12(8.6)$ & 0.58 & $9(11.0)$ & $3(20.0)$ & $6(9.0)$ & 0.22 \\
\hline Fasting insulin, ${ }^{\mp} \mathrm{mlU} / \mathrm{L}$ & $5.3(2.5-8.6)$ & $4.3(2.7-9.0)$ & $5.5(2.5-8.6)$ & 0.24 & $5.0(2.8-8.9)$ & $3.7(1.5-10.5)$ & $5.2(3.3-8.5)$ & 0.45 \\
\hline $\mathrm{HOMA}-\mathrm{IR}^{\ddagger}$ & $1.1(0.5-1.8)$ & $0.9(0.5-1.9)$ & $1.15(0.5-1.8)$ & 0.26 & $1.0(0.5-1.9)$ & $0.6(0.3-2.1)$ & $1.1(0.6-1.8)$ & 0.50 \\
\hline Triglycerides, ${ }^{\ddagger} \mathrm{mmol} / \mathrm{L}$ & $0.9(0.7-1.2)$ & $1.0(0.8-1.4)$ & $0.8(0.6-1.0)$ & 0.015 & $0.8(0.7-1.2)$ & $0.8(0.7-1.2)$ & $0.9(0.7-1.2)$ & 0.71 \\
\hline
\end{tabular}

*SDSP, symptomatic distal sensory polyneuropathy; OGT, oral glucose tolerance test; HOMA-IR, homeostatic model assessment of insulin resistance; ND, no data.

${ }^{\dagger}$ Bolded $P$-values denote statistical significance $(P<0.05)$.

${ }^{\ddagger}$ Median (interquartile range). 
while $43 \%$ were receiving treatment at study entry. Only seven of those on TB therapy (23\%) were receiving $25 \mathrm{mg}$ vitamin B6 supplementation. The median CD $4+$ cell count was 156 cells $/ \mathrm{mm}^{3}$. At study entry, almost all participants $(\geq 95 \%)$ were also receiving cotrimoxazole and vitamin Bcomplex supplements.

Follow-up Characteristics. Among the 184 participants who were examined at baseline (pre-ART), $160(86 \%)$ had at least one follow-up assessment and $102(55 \%)$ completed 24 months of follow-up. The median attrition rate per visit was $12 \%$. Participants who were lost to follow-up did not differ significantly from those who remained in the study when comparing baseline characteristics and baseline sensory neuropathy status between the two groups (data not shown).

Of those with follow-up data, 100 (61\%) participants began ART with a stavudine-containing regimen, $46(28 \%)$ with a tenofovir-containing regimen and 18 (11\%) with a zidovudinecontaining regimen. ART data are missing for 1 participant. Eight participants started TB treatment after study entry. At 6 months, viral control (viral load $<20$ copies $/ \mathrm{ml}$ ) was noted in 82 participants $(86 \%)$ and CD4 + cell counts improved from a median of 156 (IQR, 113-195) cells $/ \mathrm{mm}^{3}$ at baseline to 261 (IQR, 190-365) cells $/ \mathrm{mm}^{3}$. At 24 months, less than half the cohort (48\%) remained on cotrimoxazole and vitamin Bcomplex supplements with similar proportions among those with or without SDSP (Supplementary Table S1). There were no participants on anti-TB drugs and only two were receiving vitamin B6 (25 mg) supplementation.

Neuropathy before ART Initiation. Before ART initiation, $30(16 \%)$ participants had SDSP and 73 (39\%) had ADSP. Table 1 and Supplementary Table S1 compare the clinical and laboratory characteristics between baseline (pre-ART) SDSP and SDSP-free groups. Significant associations were age, waist:hip ratio, previous and current TB treatment, and higher triglyceride levels. Risk factors independently associated with baseline SDSP were previous or current TB treatment (adjusted OR, 5.4; 95\% CI, 1.9-15.2) and higher triglyceride levels $(\mathrm{OR},=1.1$ per 0.1 unit increase, 95\% CI, 1.0-1.3). No baseline characteristics showed a significant association with ADSP (data not shown).

In participants with pre-ART SDSP, pain and paresthesia were present in $83 \%$; pain was reported to be moderate-to-severe $(\mathrm{NRS} \geq 4)$ in $76 \%$ of those with pain (Supplementary Table S2). Impaired pinprick sensation was more frequent in SDSP observations than in ADSP observations $(83 \%$ vs. $33 \% ; P<0.001)$. In $30 \%$ of $\mathrm{SDSP}$ observations, abnormal pinprick sensation was the only abnormal sign elicited. Impaired vibration sensation was also more frequent in the SDSP group than in the ADSP group $(P=0.015)$. Altered position sense in the toes was evident in $17(9 \%)$ and similar in those with or without neuropathic symptoms. Before ART initiation, 7 (4\%) participants had neuropathic symptoms in the absence of neuropathic signs.

Incident Symptomatic DSP after ART Initiation and Risk Factors. In participants who were SDSP-free at baseline, incident SDSP occurred at a rate of 17.8 per 100 person-years; 95\% CI, 12.7-25.1), with a higher rate of incident SDSP during the first 6 months (46.0 per 100 person-years; 95\% CI, 30.9$69.9)$. Incident SDSP was associated with age $\geq 40$ years (HR, 3.0, 95\% CI, 1.5-6.1) and inversely associated with fasting insulin levels (HR, 0.8; 95\% CI, 0.6-1.0). On multivariate analysis, the association with fasting insulin remained significant (adjusted HR, 0.8; 95\% CI, 0.6-1.0), but the association with age did not. Use of stavudine also did not significantly predict onset of SDSP (HR, 1.4; 95\% CI, 0.7-2.7), nor did ADSP at baseline (HR, 1.6; $95 \%$ CI, 0.8-3.2).

Of the 102 participants remaining in the study at the 24-month evaluation, 18 (18\%) had SDSP and $63(62 \%)$ ADSP (Table 1 and Supplementary Table S1). At this final visit, SDSP was associated with older age and higher glucose levels after the oral glucose tolerance test. In contrast to the baseline (pre-ART) association, the fasting triglyceride levels were similar between the SDSP and SDSPfree group.

Evolution of Neuropathic Symptoms and Signs. Individual neuropathic scores (NRS for symptoms, TNSr for symptoms and signs) were evaluated longitudinally from the first observation of an abnormality until censoring (Table 2). Pain scores showed improvement in over $50 \%$ of participants ever experiencing pain; the mean improvement in the NRS (among those who did improve their scores) was 4.5 and the mean improvement in TNSr was 1.6. Only a minority $(9 \%)$ experienced worsening of pain. Improvement in pinprick and vibration sensation scores was noted in $37 \%$ and $40 \%$, respectively, while fewer (29\%) showed improvement in reflexes. Abnormal position sensation at the distal toes was detected in two cases with ADSP (2\%) by 24 months.

The prevalence of symptoms and signs at follow-up visits was compared with baseline (preART) prevalence in the overall cohort (Fig. 1; Table 3). The prevalence of symptoms remained statistically unchanged throughout the study, aside from an isolated increase at the 3-month visit for 
Table 2. Evolution of neuropathic symptoms and signs between first occurrence of abnormality to last follow-up

\begin{tabular}{lccccccc}
\hline & $\begin{array}{c}\text { Total } n, \\
(\%)\end{array}$ & $\begin{array}{c}\text { No follow-up } \\
n(\%)\end{array}$ & $\begin{array}{c}\text { No change } \\
n(\%)\end{array}$ & $\begin{array}{c}\text { Improved } \\
n(\%)\end{array}$ & $\begin{array}{c}\text { Absolute score } \\
\text { decrease } \\
\text { Mean (SEM) }\end{array}$ & $\begin{array}{c}\text { Worsened }^{\dagger} \\
n(\%)\end{array}$ & $\begin{array}{c}\text { Absolute score } \\
\text { increase } \\
\text { Mean (SEM) }\end{array}$ \\
\hline $\begin{array}{l}\left.\text { Symptoms (NRS }{ }^{*}\right) \\
\quad \text { Pain }\end{array}$ & $58(31.4)$ & $9(15.5)$ & $13(22.4)$ & $31(53.5)$ & $-4.5(0.4)$ & $5(8.6)$ & $3.4(0.4)$ \\
$\quad$ Paresthesia & $59(31.9)$ & $12(20.3)$ & $9(17.0)$ & $32(54.2)$ & $-5.2(0.4)$ & $5(8.8)$ & $2.4(0.4)$ \\
$\quad$ Numbness & $51(27.6)$ & $6(11.8)$ & $7(13.7)$ & $31(60.8)$ & $-4.9(0.5)$ & $7(13.3)$ & $2.9(0.3)$ \\
$\quad$ Symptoms (TNSr $\left.{ }^{\dagger}\right)$ & $75(40.5)$ & $16(21.3)$ & $13(17.3)$ & $38(50.7)$ & $-1.6(0.1)$ & $8(10.7)$ & $1.5(0.2)$ \\
Signs (TNSr) & & & & & & & \\
$\quad$ Pinprick & $108(58.4)$ & $19(17.6)$ & $20(18.5)$ & $40(37.0)$ & $-1.8(0.1)$ & $29(26.9)$ & $1.2(0.1)$ \\
$\quad$ Vibration & $77(41.6)$ & $14(18.2)$ & $20(26.0)$ & $31(40.2)$ & $-1.9(0.2)$ & $12(15.6)$ & $1.6(0.2)$ \\
$\quad$ Reflexes & $133(71.9)$ & $20(15.1)$ & $43(32.3)$ & $38(28.6)$ & $-1.1(0.1)$ & $32(24.1)$ & $1.5(0.1)$ \\
\hline
\end{tabular}

${ }^{*}$ From the BPNS. ${ }^{11}$

${ }^{+}$See Reference 2.

paresthesia and numbness. In contrast, the prevalence of signs was higher at almost all follow-up visits. The prevalence of symptom and sign at followup visits was compared with baseline prevalence in and between groups: (A) group that entered the study with SDSP versus group that entered the study SDSP-free; and (B) group initiated on a stavudine-containing regimen versus group initiated on a non-stavudine-containing regimen. In analysis A, the prevalence of pain and paresthesia was noted to decrease at each follow-up visit in the baseline SDSP group (month 18 vs. month 0; OR, $0.09 ; 95 \%$ CI, 0.03-0.29), while symptom prevalence increased in the SDSP-free group (Fig. 2A; Supplementary Table S3). The prevalence profiles for symptoms differed significantly between the two groups at all follow-up visits. Prevalence of signs increased significantly in the baseline SDSP-

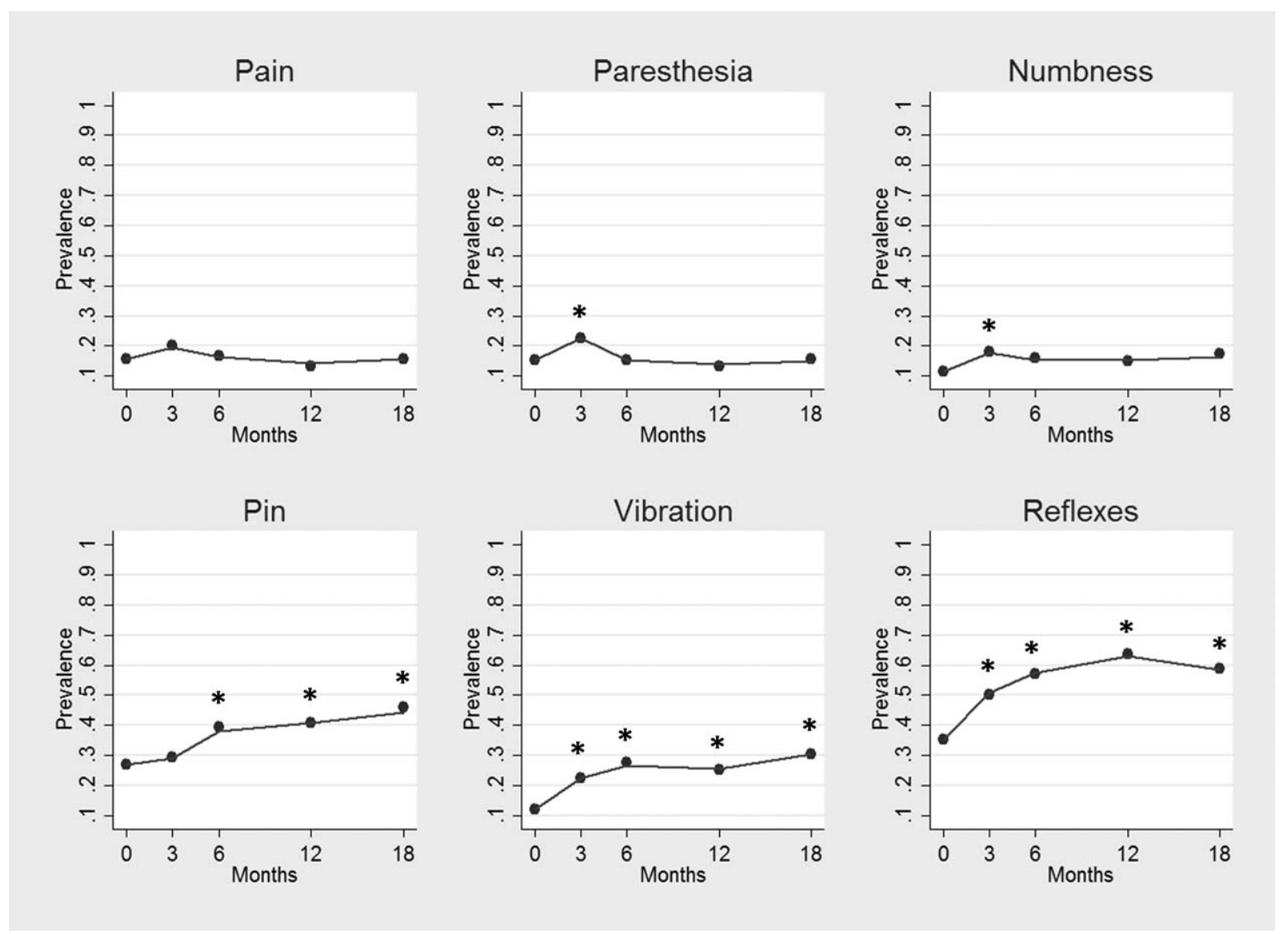

FIGURE 1. Modeled prevalence of neuropathic symptoms and signs at each visit over 18 months. *Significant difference in prevalence between indicated visit and baseline (pre-ART) visit. Refer to Table 2 for estimated ORs and 95\% Cls. 


\begin{tabular}{|c|c|c|c|c|}
\hline & $\begin{array}{r}\text { Month } 3 \text { vs. } 0 \\
\text { OR }(95 \% \text { Cl) }\end{array}$ & $\begin{array}{r}\text { Month } 6 \text { vs. } 0 \\
\text { OR }(95 \% \text { Cl) }\end{array}$ & $\begin{array}{c}\text { Month } 12 \text { vs. } 0 \\
\text { OR }(95 \% \text { Cl) }\end{array}$ & $\begin{array}{c}\text { Month } 18 \text { vs. } 0 \\
\text { OR }(95 \% \text { Cl) }\end{array}$ \\
\hline \multicolumn{5}{|l|}{ Symptoms } \\
\hline Pain & $1.31(0.86-2.00)$ & $1.05(0.66-1.65)$ & $0.89(0.55-1.46)$ & $1.00(0.60-1.66)$ \\
\hline Paresthesia & 1.62 (1.07-2.47) & $1.01(0.64-1.62)$ & $0.91(0.56-1.50)$ & $0.18(0.60-1.67)$ \\
\hline Numbness & $1.68(1.07-2.64)$ & $1.42(0.88-2.30)$ & $1.40(0.85-2.32)$ & $1.53(0.91-2.56)$ \\
\hline \multicolumn{5}{|l|}{ Signs } \\
\hline Pinprick & $1.10(0.78-1.56)$ & 1.65 (1.16-2.33) & $1.85(1.29-2.66)$ & $2.14(1.47-3.12)$ \\
\hline Vibration & $2.13(1.37-3.34)$ & $2.68(1.71-4.20)$ & $2.54(1.60-4.05)$ & $3.25(2.02-5.22)$ \\
\hline Reflexes & $1.90(1.38-2.61)$ & 2.50 (1.80-3.49) & $3.14(2.21-4.45)$ & $2.60(1.80-3.74)$ \\
\hline
\end{tabular}

*Bolded data denote statistical significance

free group, while prevalence of signs in the baseline SDSP group remained relatively statistically unchanged, aside for an initial drop in prevalence at 3 months for abnormal pinprick sensation and an increase at 6 months for reduced/absent reflexes. Overall, the profiles for abnormal pinprick sensation differed significantly between the baseline SDSP versus SDSP-free groups at all follow-up visits.

In analysis $\mathrm{B}$, participants who received stavudine had a higher baseline prevalence of pain compared with those who were started on a nonstavudine-containing regimen (Fig. 2B; Supplementary Table S4). These patients also had lower $\mathrm{CD} 4+$ cell counts, because the governmentsponsored ART program enrolled participants with lower CD $4+$ cell counts $\left[\leq 200 / \mathrm{mm}^{3}\right]$ while stavudine was in use, whereas the switch to tenofovir cooccurred with starting ART when CD4 + cell counts were higher $\left[\leq 350 / \mathrm{mm}^{3}\right]$. Nevertheless, symptom prevalence did not differ significantly between the two groups thereafter. Both groups experienced an increasing prevalence of signs, but the increase in prevalence for reduced/absent reflexes was significantly greater in the stavudine group for months 6, 12 and 18 (OR, 2.24; 95\% CI, 1.08-4.65 for stavudine vs. non-stavudine at 18months). An analysis comparing the group with baseline CD $4+$ cell count $\leq 200 / \mathrm{mm}^{3}$ versus the group with $\mathrm{CD} 4+$ cell count $>200 / \mathrm{mm}^{3}$ did not demonstrate the same effects (data not shown).

In an exploratory analysis, we compared participants who entered the study with ADSP to those who entered the study free of both ADSP and SDSP (Supplementary Fig. S1). This analysis showed a trend for a higher proportion of the ADSP group to have painful symptoms at follow-up at visits when compared with those free of both ADSP and SDSP pre-ART. However, the survival analysis did not significantly support this observation.

\section{Discussion}

We found SDSP in $16 \%$ and ADSP in $39 \%$ of ART-naïve patients immediately before starting
ART, suggesting a substantial background prevalence of pre-existing HIV-associated sensory neuropathy. Pre-ART SDSP was independently associated with current or previous TB / TB treatment and higher fasting triglyceride levels. Although older age is frequently identified as a risk factor for HIV-associated DSP, it did not remain associated with SDSP in a multivariate analysis. We and others have found a high prevalence of sensory neuropathy in HIV/TB co-infected patients in similar settings. ${ }^{3,13}$ Earlier initiation of ART may reduce the high prevalence of sensory neuropathy demonstrated in this study by reducing exposure to HIV-induced oxidative stress ${ }^{6}$ and Coinfection with TB. It is worth mentioning that only a minority of participants enrolled in this study were prescribed supplementary vitamin $\mathrm{B} 6$ by the clinic during TB treatment. ${ }^{7}$ Supplementation with vitamin $\mathrm{B} 6$ has been shown to prevent the sensory neuropathy associated with isoniazid. ${ }^{14}$ Although vitamin B12 deficiency has been reported in 10\% in a similar population, ${ }^{15}$ we found macrocytic anemia (a proxy for vitamin B12 deficiency) in only three participants at baseline.

There were some "metabolic" signals which associated with SDSP in this black, relatively young African cohort (which characteristically comprises predominantly women) ${ }^{1,2}$ We replicated our previous observations that higher waist:hip ratios (univariate analysis) and fasting triglycerides levels associated with SDSP pre-ART. ${ }^{2}$ Although the latter association has been observed in an ART-treated cohort, ${ }^{16}$ we did not demonstrate higher fasting triglyceride levels in SDSP after 24 months of ART. It is unclear whether the substantially lower level of absolute fasting triglycerides in our African cohort compared with nonfasting results from firstworld cohorts ${ }^{16,17}$ is due to the timing of the blood draws, or whether it suggests the absolute triglyceride level is not itself critical, but rather a surrogate biomarker for painful neuropathy. The latter explanation is supported by the plateau in prevalence of painful SDSP after 6 months of ART 
A)

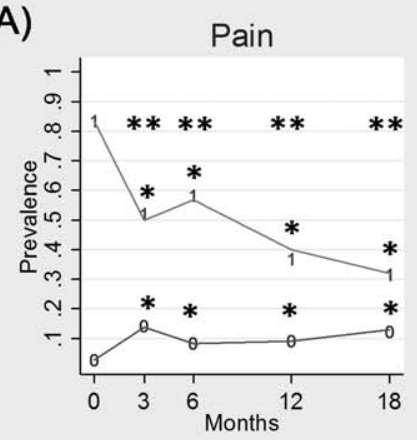

Pinprick

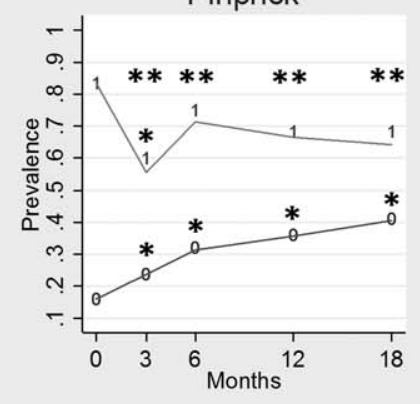

Paresthesia

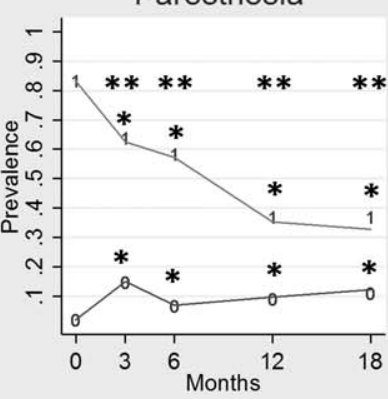

Vibration

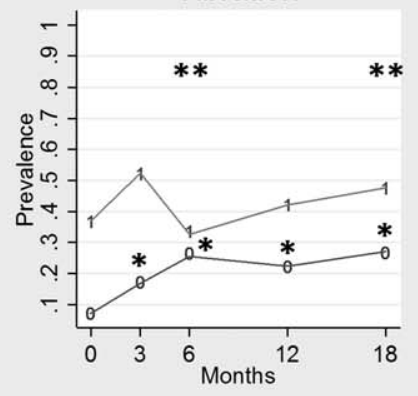

Numbness

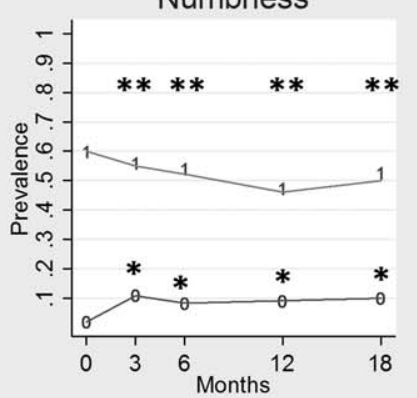

Reflexes

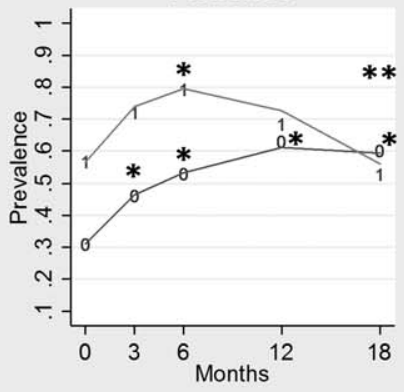

B)

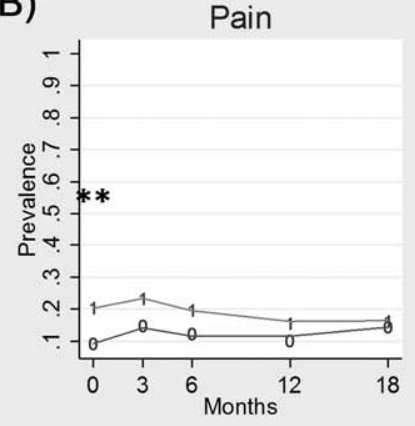

Pinprick

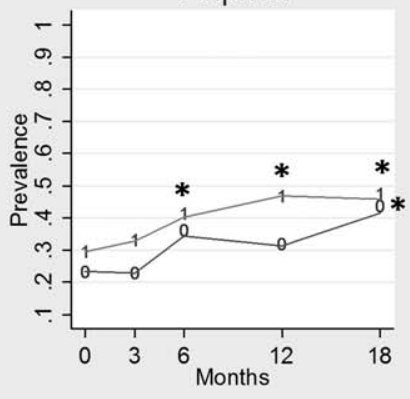

Paresthesia

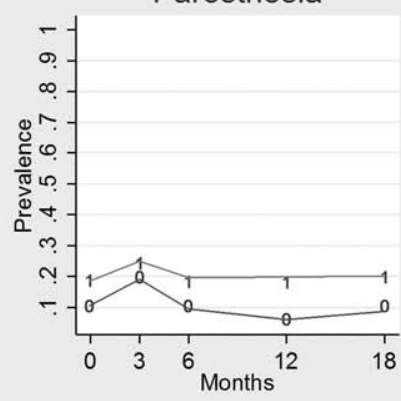

Vibration

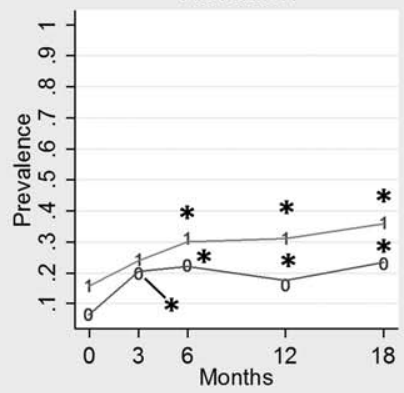

Numbness

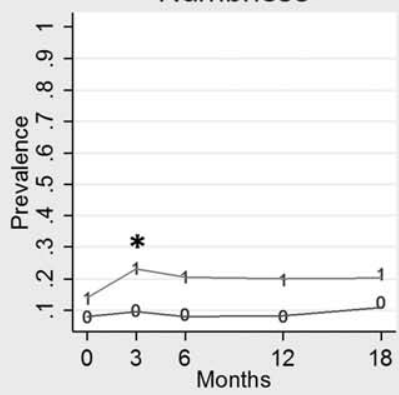

Reflexes

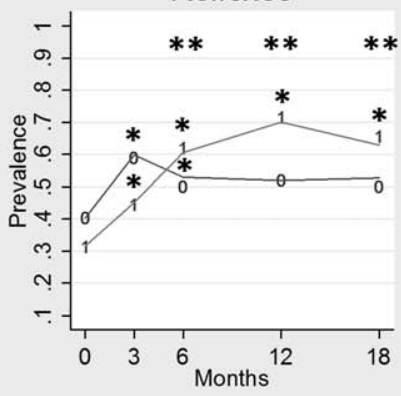

FIGURE 2. Modeled prevalence of neuropathic symptoms and signs at each visit over 18 months in and between groups: group that entered the study with baseline (pre-ART) SDSP ("1") and group that entered the study free of SDSP ("0") (A); and group that received a stavudine-containing regimen ("1") and group that received a non-stavudine-containing regimen ("0") (B). *Significant difference in prevalence between indicated visit and baseline visit. ${ }^{*}$ Significant difference in prevalence profile between groups at indicated visit. Refer to Supplementary Tables S3 and S4 for estimated ORs and 95\% Cls.

coupled with the loss of the association signal between SDSP and fasting triglycerides at 24 months.
Our results confirm that patients are most at risk of developing SDSP either before or within the first 3 to 6 months of initiating ART. ${ }^{4,6}$ 
Incident SDSP (in those SDSP-free at study entry) occurred at a higher rate during the first 6 months (46 per 100 person-years) compared with the overall study period (18 per 100 person-years). The onset of SDSP coincided with the time window in which a potentiation of dysregulated systemic inflammatory signals has been observed after ART initiation, irrespective of the pre-ART CD4 + cell count. ${ }^{6,18}$ Incident SDSP was inversely associated with fasting insulin. Insulin has been shown to exert a regenerative effect and improve mitochondrial function in vitro. ${ }^{19,20}$ Noninsulin glucoselowering drugs have also been shown to have a neuro-protective effect in HIV-associated sensory neuropathy. ${ }^{21}$ It is noteworthy that our patients had not received statins or hypoglycemic medications. Intriguingly, patients with painful SDSP do not respond to standard symptomatic therapies that provide relief in similarly painful diabetic and other neuropathies. ${ }^{1,22,23}$ Although some symptomatic participants in this study received therapies for pain (35\% of symptomatic visits; mainly amitriptyline), the study design precluded estimation of potential benefit of these therapies.

While a small proportion (9-13\%) of participants experienced mild-to-moderate worsening of their symptoms over time, more than half experienced a substantial improvement in their symptoms with a mean absolute decrease in worst pain score of 4.5 (on an 11-point scale) and a proximal regression in anatomical extent (as measured by the 4-point TNSr scale). Experimental models suggest that painful symptoms are driven and maintained by exposure to HIV proteins such as gp120 and HIV-induced inflammatory cascades in the nerve cell body and axon. ${ }^{1,24}$ Viral clearance and the relative stabilization of immune dysregulation with successful ART may potentially account for the reduction in the HIVassociated small fiber painful neuropathic symptoms seen in participants with pre-existing HIV-associated SDSP. These results underscore the benefit anticipated from earlier ART initiation.

In contrast to the predominant improvement in symptoms, improvement of neuropathic signs was observed less frequently and the prevalence of signs in the overall cohort increased significantly at each visit. By 24 months, the proportion of participants with ADSP increased from 39\% at baseline (pre-ART) to $62 \%$, a finding in keeping with previous reports of ADSP in long-term cohorts. ${ }^{8}$ The accumulation of clinical evidence of nerve dysfunction may be attributed to the slow transport of dysfunctional mitochondria down axons over months to years and the particular susceptibility of distal sensory axons to mitochondrial defects. ${ }^{25,26}$ Of interest, despite the increasing prevalence of neuropathic signs sub-served by small (pinprick) and larger myelinated sensory fibers (reflexes and vibration), position sensation loss stayed low in the first 2 years after ART initiation. It remains to be seen whether early inflammation will impact on subsequent mitochondrial dysfunction; however, our data do not suggest that those with early SDSP subsequently accumulate neuropathic signs.

The study provided a unique opportunity to prospectively compare sensory neuropathy between patients treated with a dideoxynucleotide reverse transcriptase inhibitor (stavudine) and those treated with other classes of antiretrovirals, as the study coincided with the phase-out of stavudine and the introduction of tenofovir-containing regimens in first-line ART regimens in South Africa. The use of stavudine did not significantly predict the onset of SDSP, but did result in increasing prevalence of reduced/absent reflexes compared with the nonstavudine group. The clinical relevance of impaired reflexes is uncertain. It should be noted that participants who were started on stavudine (as per program guidelines) had a higher prevalence of painful symptoms before commencing ART, possibly because of lower CD4 + cell counts seen before the phase-out of stavudine. These patients may have been identified using a routine symptom screen. ${ }^{27}$ During this study, none of the patients were switched by their clinic health workers from their initial first-line regimen.

As mentioned, abnormal pinprick sensation was noted in a high proportion with SDSP, similar to our previous findings ${ }^{2}$; in a third, impaired pinprick sensation was the only neuropathic sign elicited. The BPNS, used in many studies, excludes this easy to perform bedside test of small fiber function, potentially missing DSP in several patients. ${ }^{3}$ Although this modality has utility in resource-limited settings lacking tools and expertise for proper assessment of vibration sensation and reflexes, our results suggest that the symptomonly screening tool ${ }^{27}$ will over call SDSP in only a small subset (4\%) who had isolated neuropathic symptoms in the absence of signs.

The study experienced loss-to-follow-up at a rate of $12 \%$ per visit. Some loss-to-follow-up may have been attributed to migration or limited access. An analysis of baseline characteristics and outcomes between patients who remained in the study and those lost to follow-up at each visit suggested that this loss was at random; ${ }^{28}$ however, attrition bias cannot be excluded. We used a mixed-effect model that accounts for loss-to-follow-up in the longitudinal analysis and performed an imputed longitudinal analysis that produced similar results to an unimputed analysis (data not shown).

This cohort was substantially smaller than the multi-centered North American cohorts; ${ }^{8,9,21}$ 
however, strengths of the study include prospective longitudinal assessments from just before starting ART, study visits at regular time intervals thereafter, and examination by the same doctors, thereby minimizing inter-rater bias. ${ }^{29}$ In this prospective study, we used a DSP definition of at least 1 neuropathic sign as we were assessing signs from a known baseline, which improved specificity without having to use stricter criteria, and allows for comparison with other studies. All metabolic and lipid parameters were assessed in a fasting state. A limitation may be that a history of diabetes at baseline resulted in exclusion from this study, but despite this exclusion there was an association between SDSP and higher glucose levels after the oral glucose tolerance test after 2 years of ART. This observation requires careful attention in the follow-up of these cases in HIV treatment programs. The relatively advanced immunosuppression observed in this study (median pre-ART CD4 + cell count $=156$ cells $/ \mathrm{mm}^{3}$ ), which also resulted in high proportions of concomitant cotrimoxazole use at ART initiation, limits generalizability of these data to cohorts initiating ART at higher CD4 + cell counts.

In conclusion, we have studied the clinical evolution of neuropathic symptoms and signs in a typical African community-based cohort comprising predominantly younger women with relatively advanced HIV-infection at the time of ART initiation. Neuropathic pain largely improved in response to ART, although a proportion developed new painful neuropathic symptoms. Increasing prevalence of neuropathic signs without symptoms appeared to be related to the accrual of both small and large fiber dysfunction.

We thank Sr. Carmen Delport, Chantal Stuart, Malibongwe Majola, Nick Faunce, and the staff at Crossroads Community Health Centre, Cape Town.

Ethical Publication Statement: We (the authors) confirm that we have read the Journal's position on issues involved in ethical publication and affirm that this report is consistent with those guidelines.

\section{REFERENCES}

1. Centner CM, Bateman KJ, Heckmann JM. Manifestations of HIV infection in the peripheral nervous system. Lancet Neurol 2013;12: 295-309.

2. Maritz J, Benatar M, Dave JA, Harrison TB, Badri M, Levitt NS, et al. HIV neuropathy in South Africans: frequency, characteristics, and risk factors. Muscle Nerve 2010;41:599-606.

3. Centner CM, Carrara H, Harrison TB, Benatar M, Heckmann JM. Sensory polyneuropathy in human immunodeficiency virus-infected patients receiving tuberculosis treatment. Int J Tuberc Lung Dis 2014;18:27-33.

4. Arenas-Pinto A, Bhaskaran K, Dunn D, Weller IV. The risk of developing peripheral neuropathy induced by nucleoside reverse transcriptase inhibitors decreases over time: evidence from the Delta trial. Antivir Ther 2008;13:289-295.

5. Mehta SA, Ahmed A, Laverty M, Holzman RS, Valentine F, Sivapalasingam S. Sex differences in the incidence of peripheral neuropathy among Kenyans initiating antiretroviral therapy. Clin Infect Dis 2011;53:490-496.
6. Van der Watt JJ, Wilkinson KA, Wilkinson RJ, Heckmann JM. Plasma cytokine profiles in HIV-1 infected patients developing neuropathic symptoms shortly after commencing antiretroviral therapy: a casecontrol study. BMC Infect Dis 2014;14:71.

7. van der Watt JJ, Benatar MG, Harrison TB, Carrara H, Heckmann JM. Isoniazid exposure and pyridoxine levels in human immunodeficiency virus associated distal sensory neuropathy. Int J Tuberc Lung Dis 2015;19:1312-1319.

8. Evans SR, Ellis RJ, Chen H, Yeh TM, Lee AJ, Schifitto G, et al. Peripheral neuropathy in HIV: prevalence and risk factors. AIDS 2011;25:919-928.

9. Lee AJ, Bosch RJ, Evans SR, Wu K, Harrison T, Grant P, et al. Patterns of peripheral neuropathy in ART-naive patients initiating modern ART regimen. J Neurovirol 2015;21:210-218.

10. Sacktor N, Nakasujja N, Skolasky RL, Robertson K, Musisi S, Ronald A, et al. Benefits and risks of stavudine therapy for HIV-associated neurologic complications in Uganda. Neurology 2009;72:165-170.

11. Cherry CL, Wesselingh SL, Lal L, McArthur JC. Evaluation of a clinical screening tool for HIV-associated sensory neuropathies. Neurology 2005;65:1778-1781.

12. Farrar JT, Young JP Jr, LaMoreaux L, Werth JL, Poole RM. Clinical importance of changes in chronic pain intensity measured on an 11point numerical pain rating scale. Pain 2001;94:149-158.

13. Arenas-Pinto A, Thompson J, Musoro G, Musana H, Lugemwa A, Kambugu A, et al. Peripheral neuropathy in HIV patients in subSaharan Africa failing first-line therapy and the response to secondline ART in the EARNEST trial. J Neurovirol 2016;22:104-113.

14. van der Watt JJ, Harrison TB, Benatar M, Heckmann JM. Polyneuropathy, anti-tuberculosis treatment and the role of pyridoxine in the HIV/AIDS era: a systematic review. Int J Tuberc Lung Dis 2011;15:722-728.

15. Semeere AS, Nakanjako D, Ddungu H, Kambugu A, Manabe YC, Colebunders R. Sub-optimal vitamin B-12 levels among ART-naive HIV-positive individuals in an urban cohort in Uganda. PLoS One 2012;7:e40072.

16. Banerjee S, McCutchan JA, Ances BM, Deutsch R, Riggs PK, Way L, et al. Hypertriglyceridemia in combination antiretroviral-treated HIVpositive individuals: potential impact on HIV sensory polyneuropathy. AIDS 2011;25:F1-F6.

17. Phillips TJ, Brown M, Ramirez JD, Perkins J, Woldeamanuel YW, Williams AC, et al. Sensory, psychological, and metabolic dysfunction in HIV-associated peripheral neuropathy: a cross-sectional deep profiling study. Pain 2014;155:1846-1860.

18. Sereti I, Krebs SJ, Phanuphak N, Fletcher JL, Slike B, Pinyakorn S, et al. Persistent, albeit reduced, chronic inflammation in persons starting antiretroviral therapy in acute HIV infection. Clin Infect Dis 2017:64:124-131.

19. Nisr RB, Affourtit C. Insulin acutely improves mitochondrial function of rat and human skeletal muscle by increasing coupling efficiency of oxidative phosphorylation. Biochim Biophys Acta 2014;1837:270-276.

20. Ish-Shalom D, Christoffersen CT, Vorwerk P, Sacerdoti-Sierra N, Shymko RM, Naor D, et al. Mitogenic properties of insulin and insulin analogues mediated by the insulin receptor. Diabetologia 1997 40(Suppl 2):S25-S31.

21. Evans SR, Lee AJ, Ellis RJ, Chen H, Wu K, Bosch RJ, et al. HIV peripheral neuropathy progression: protection with glucose-lowering drugs? J Neurovirol 2012;18:428-433.

22. Dinat N, Marinda E, Moch S, Rice AS, Kamerman PR. Randomized, double-blind, crossover trial of amitriptyline for analgesia in painful HIV-associated sensory neuropathy. PLoS One 2015;10:e0126297.

23. Simpson DM, Rice AS, Emir B, Landen J, Semel D, Chew ML, et al. A randomized, double-blind, placebo-controlled trial and open-label extension study to evaluate the efficacy and safety of pregabalin in the treatment of neuropathic pain associated with human immunodeficiency virus neuropathy. Pain 2014;155:1943-1954.

24. Kamerman PR, Moss PJ, Weber J, Wallace VC, Rice AS, Huang W. Pathogenesis of HIV-associated sensory neuropathy: evidence from in vivo and in vitro experimental models. J Peripher Nerv Syst 2012;17: $19-31$.

25. Lehmann HC, Chen W, Borzan J, Mankowski JL, Hoke A. Mitochondrial dysfunction in distal axons contributes to human immunodeficiency virus sensory neuropathy. Ann Neurol 2011;69:100-110.

26. Cashman CR, Hoke A. Mechanisms of distal axonal degeneration in peripheral neuropathies. Neurosci Lett 2015;596:33-50.

27. Kandiah PA, Atadzhanov M, Kvalsund MP, Birbeck GL. Evaluating the diagnostic capacity of a single-question neuropathy screen (SQNS) in HIV positive Zambian adults. J Neurol Neurosurg Psychiatry 2010;81:1380-1381.

28. Kristman V, Manno M, Cote P. Loss to follow-up in cohort studies: how much is too much? Eur J Epidemiol 2004;19:751-760.

29. Simpson DM, Kitch D, Evans SR, McArthur JC, Asmuth DM, Cohen B, et al. HIV neuropathy natural history cohort study: assessmen measures and risk factors. Neurology 2006;66:1679-1687. 
8) Supplementary material (Muscle \& Nerve) 
Supplementary Table 1. Additional baseline (pre-antiretroviral therapy) and 24-month clinical and laboratory characteristics by symptomatic distal sensory polyneuropathy status.

\begin{tabular}{|c|c|c|c|c|c|c|c|c|}
\hline \multirow[b]{2}{*}{ Characteristic } & \multicolumn{4}{|c|}{ Baseline } & \multicolumn{4}{|c|}{ 24-month } \\
\hline & $\begin{array}{c}\text { Total } \\
\mathrm{N}=184\end{array}$ & $\begin{array}{l}\text { SDSP } \\
\mathrm{N}=30\end{array}$ & $\begin{array}{l}\text { SDSP-free } \\
N=154\end{array}$ & $\begin{array}{l}\mathrm{P} \text { - } \\
\text { value }\end{array}$ & $\begin{array}{c}\text { Total } \\
\mathrm{N}=102\end{array}$ & $\begin{array}{l}\text { SDSP } \\
\mathrm{N}=18\end{array}$ & $\begin{array}{c}\begin{array}{c}\text { SDSP-free } \\
\mathrm{N}=84\end{array}\end{array}$ & $\begin{array}{l}P- \\
\text { value }\end{array}$ \\
\hline Concomitant therapies, $\mathrm{N}(\%)$ & & & & & & & & \\
\hline Cotrimoxazole & $179(97)$ & $30(100)$ & $149(97)$ & & $49(48)$ & $9(50)$ & $40(48)$ & \\
\hline Vitamin B complex* & $175(95)$ & $30(100)$ & $145(94)$ & & $48(47)$ & $9(50)$ & $39(46)$ & \\
\hline Vitamin B6 (25mg) & $14(8)$ & $7(23)$ & $7(5)$ & 0.002 & $2(2)$ & 0 & $2(2)$ & \\
\hline Weight $^{\dagger}, \mathrm{kg}$ & $62.0(55-71)$ & $62(54-73)$ & $62(55-71)$ & 0.95 & $70.1(59.4-82)$ & $72.6(57.7-79.7)$ & $68.8(61.0-82.9)$ & 0.86 \\
\hline Systolic blood pressure ${ }^{\dagger}, \mathrm{mmHg}$ & $111(103-121)$ & $109(100-119)$ & $111(103-121)$ & 0.39 & $114(104-123)$ & $117(107-127)$ & $113(103-123)$ & 0.47 \\
\hline $\begin{array}{l}\text { Diastolic blood pressure }{ }^{\dagger}, \\
\mathrm{mmHg}\end{array}$ & $72(66-79)$ & $70(66-77)$ & $73(66-80)$ & 0.26 & $73(67-81)$ & $77(66-85)$ & $73(67-79)$ & 0.38 \\
\hline WHO HIV stage, N (\%) & & & & 0.43 & & & & \\
\hline Stage 1 & $58(32.2)$ & $8(27.6)$ & $50(33.1)$ & & ND & ND & ND & \\
\hline Stage 2 & $58(32.2)$ & $7(24.1)$ & $51(33.7)$ & & ND & ND & ND & \\
\hline Stage 3 & $57(31.7)$ & $12(41.4)$ & $45(29.8)$ & & ND & ND & ND & \\
\hline Stage 4 & $7(3.9)$ & $2(6.9)$ & $5(3.3)$ & & ND & ND & ND & \\
\hline Total cholesterol ${ }^{\dagger}, \mathrm{mmol} / \mathrm{L}$ & $3.7(3.2-4.2)$ & $3.7(3.0-4.3)$ & $3.7(3.2-4.2)$ & 0.33 & $4.5(3.8-4.9)$ & $4.5(4.0-5.0)$ & $4.4(3.8-5.00)$ & 0.75 \\
\hline $\mathrm{HDL}^{\dagger}, \mathrm{mmol} / \mathrm{L}$ & $1.0(0.8-1.1)$ & $0.9(0.8-1.1)$ & $1.0(0.8-1.1)$ & 0.30 & $1.6(1.2-1.8)$ & $1.6(1.2-1.8)$ & $1.4(1.2-1.8)$ & 0.56 \\
\hline $\mathrm{LDL}^{\dagger}, \mathrm{mmol} / \mathrm{L}$ & $2.3(1.9-2.8)$ & $2.3(1.8-2.7)$ & $2.3(1.9-2.9)$ & 0.22 & $2.3(1.9-3.0)$ & $2.3(2.1-3.1)$ & $2.2(1.9-3.0)$ & 0.62 \\
\hline Hemoglobin ${ }^{\dagger}, \mathrm{g} / \mathrm{dL}$ & $11.8(10.4-12.6)$ & $11.6(9.4-12.4)$ & $11.8(10.7-12.7)$ & 0.18 & ND & ND & ND & \\
\hline
\end{tabular}

SDSP, symptomatic distal sensory polyneuropathy; WHO, World Health Organization; HDL, high density lipoprotein; LDL, low density lipoprotein. *contains $2-4 m g$ vitamin B6. ${ }^{14}$

${ }^{\dagger}$ Median (interquartile range) 
Supplementary Table 2. Distribution of baseline (pre-antiretroviral therapy) symptom scores (numerical rating scale) and sign scores (reduced Total Neuropathy Score) by symptomatic and asymptomatic distal sensory polyneuropathy status.

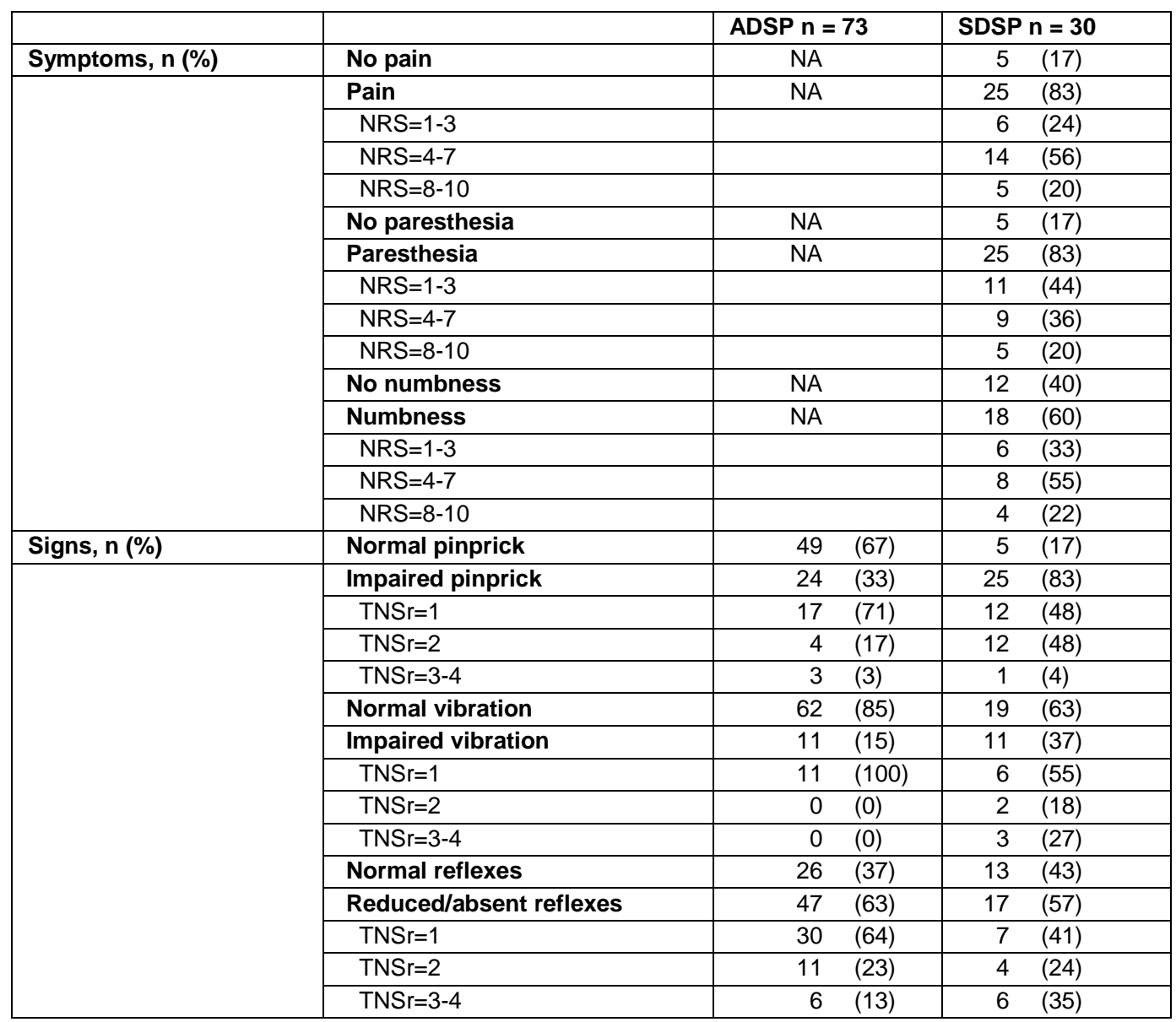

ADSP asymptomatic distal sensory polyneuropathy; SDSP, symptomatic distal sensory polyneuropathy; NRS, numeral rating scale from BPNS; TNSr (reduced Total Neuropathy Score); NA, not applicable. 
Supplementary Table 3. Comparison of symptom and sign prevalence (odds ratios) between baseline and follow-up visits by baseline symptomatic distal sensory polyneuropathy (SDSP) status (baseline SDSP vs. no baseline SDSP), and comparison between the two groups at each visit.

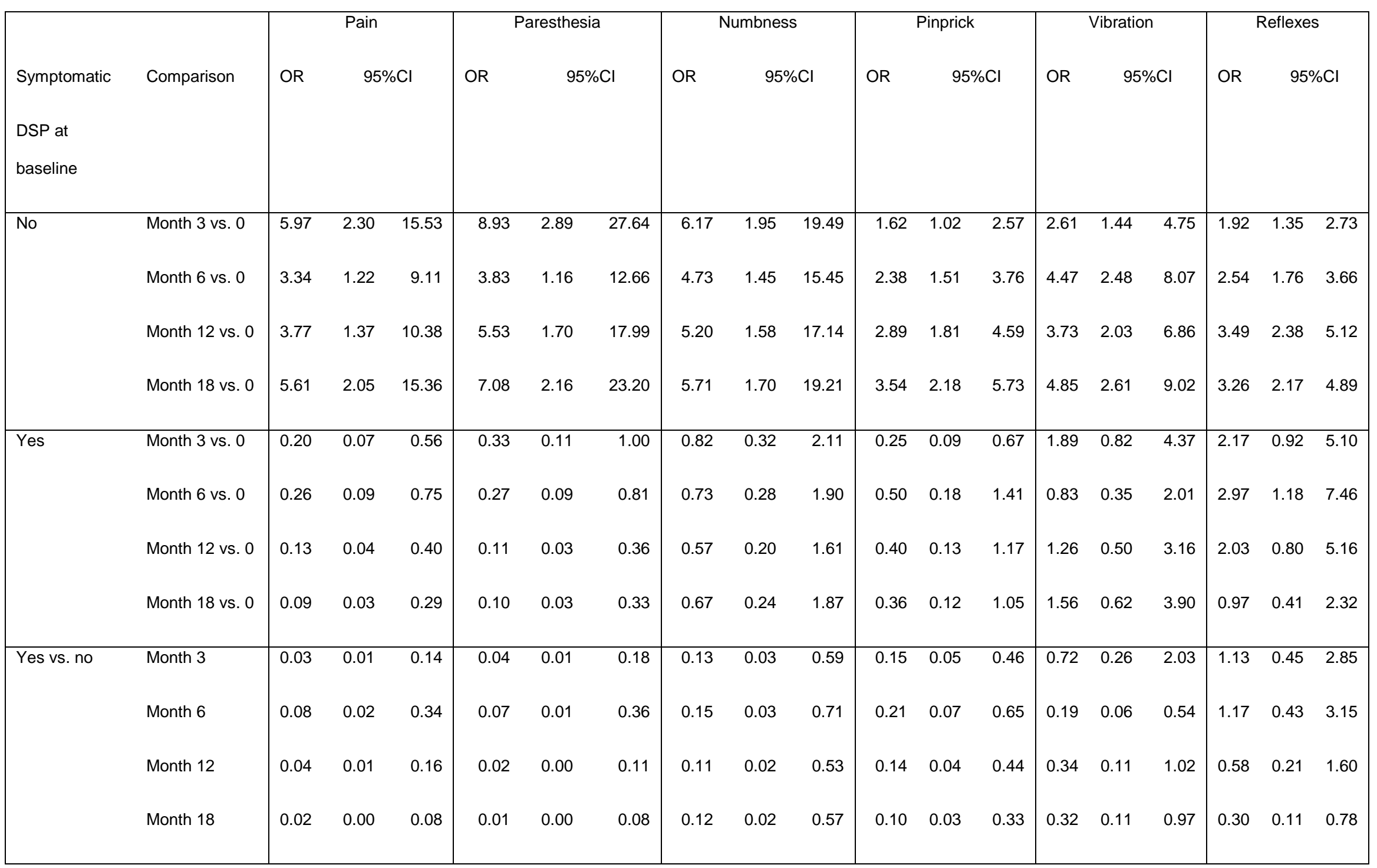


Supplementary Table 4. Comparison of symptom and sign prevalence (odds ratios, OR and 95\% confidence intervals (Cl)) between baseline and follow-up visits by stavudine regimen (participants receiving stavudine vs. not receiving stavudine), and comparison between the two groups at each visit.

\begin{tabular}{|c|c|c|c|c|c|c|c|c|c|c|c|c|c|c|c|c|c|c|c|}
\hline \multirow{3}{*}{$\begin{array}{l}\text { Stavudine } \\
\text { regimen } \\
\text { No }\end{array}$} & \multirow{3}{*}{$\begin{array}{l}\text { Comparison } \\
\text { Month } 3 \text { vs. } 0\end{array}$} & \multirow{3}{*}{$\begin{array}{l}\text { OR } \\
1.65\end{array}$} & \multicolumn{2}{|l|}{ Pain } & \multicolumn{3}{|c|}{ Paresthesia } & \multicolumn{3}{|c|}{ Numbness } & \multicolumn{3}{|c|}{ Pinprick } & \multicolumn{3}{|c|}{ Vibration } & \multicolumn{3}{|c|}{ Reflexes } \\
\hline & & & \multicolumn{2}{|c|}{$95 \% \mathrm{Cl}$} & \multirow{2}{*}{$\begin{array}{l}\text { OR } \\
2.01\end{array}$} & \multicolumn{2}{|c|}{$95 \% \mathrm{Cl}$} & \multirow{2}{*}{$\begin{array}{l}\text { OR } \\
1.24\end{array}$} & \multicolumn{2}{|c|}{$95 \% \mathrm{Cl}$} & \multirow{2}{*}{$\begin{array}{l}\text { OR } \\
0.98\end{array}$} & \multicolumn{2}{|c|}{$95 \% \mathrm{Cl}$} & \multirow{2}{*}{$\begin{array}{l}\text { OR } \\
3.71\end{array}$} & \multicolumn{2}{|c|}{$95 \% \mathrm{Cl}$} & \multirow{2}{*}{$\begin{array}{l}\text { OR } \\
2.20\end{array}$} & \multicolumn{2}{|c|}{$95 \% \mathrm{Cl}$} \\
\hline & & & 0.73 & 3.70 & & 0.94 & 4.31 & & 0.51 & 2.99 & & 0.54 & 1.78 & & 1.53 & 8.98 & & 1.33 & 3.65 \\
\hline & Month 6 vs. 0 & 1.30 & 0.55 & 3.06 & 0.89 & 0.36 & 2.18 & 1.02 & 0.40 & 2.60 & 1.72 & 0.97 & 3.04 & 4.06 & 1.67 & 9.87 & 1.67 & 1.00 & 2.77 \\
\hline & Month 12 vs. 0 & 1.30 & 0.53 & 3.19 & 0.53 & 0.18 & 1.61 & 1.07 & 0.40 & 2.82 & 1.50 & 0.82 & 2.75 & 3.06 & 1.20 & 7.78 & 1.61 & 0.94 & 2.75 \\
\hline & Month 18 vs. 0 & 1.66 & 0.70 & 3.94 & 0.80 & 0.30 & 2.16 & 1.43 & 0.57 & 3.58 & 2.33 & 1.29 & 4.22 & 4.41 & 1.77 & 11.00 & 1.66 & 0.96 & 2.85 \\
\hline \multirow[t]{4}{*}{ Yes } & Month 3 vs. 0 & 1.18 & 0.72 & 1.95 & 1.45 & 0.87 & 2.42 & 1.85 & 1.09 & 3.13 & 1.16 & 0.75 & 1.80 & 1.68 & 0.98 & 2.88 & 1.79 & 1.18 & 2.70 \\
\hline & Month 6 vs. 0 & 0.95 & 0.56 & 1.63 & 1.07 & 0.61 & 1.87 & 1.60 & 0.92 & 2.79 & 1.60 & 1.03 & 2.51 & 2.29 & 1.33 & 3.94 & 3.37 & 2.18 & 5.20 \\
\hline & Month 12 vs. 0 & 0.76 & 0.42 & 1.36 & 1.08 & 0.60 & 1.92 & 1.54 & 0.86 & 2.75 & 2.09 & 1.32 & 3.30 & 2.41 & 1.38 & 4.21 & 5.10 & 3.19 & 8.15 \\
\hline & Month 18 vs. 0 & 0.77 & 0.41 & 1.46 & 1.10 & 0.59 & 2.06 & 1.56 & 0.84 & 2.90 & 2.01 & 1.23 & 3.30 & 2.99 & 1.67 & 5.38 & 3.71 & 2.27 & 6.06 \\
\hline \multirow[t]{5}{*}{ Yes vs. no } & Month 0 & 2.56 & 1.03 & 6.34 & 1.96 & 0.81 & 4.72 & 1.91 & 0.71 & 5.17 & 1.38 & 0.71 & 2.70 & 2.69 & 0.95 & 7.64 & 0.68 & 0.37 & 1.25 \\
\hline & Month 3 & 0.72 & 0.28 & 1.86 & 0.72 & 0.29 & 1.80 & 1.49 & 0.54 & 4.17 & 1.19 & 0.57 & 2.49 & 0.45 & 0.16 & 1.28 & 0.81 & 0.42 & 1.56 \\
\hline & Month 6 & 0.73 & 0.27 & 2.00 & 1.21 & 0.42 & 3.47 & 1.56 & 0.53 & 4.64 & 0.93 & 0.45 & 1.93 & 0.56 & 0.20 & 1.59 & 2.02 & 1.04 & 3.94 \\
\hline & Month 12 & 0.58 & 0.20 & 1.70 & 2.02 & 0.58 & 7.08 & 1.45 & 0.47 & 4.48 & 1.39 & 0.65 & 2.97 & 0.79 & 0.27 & 2.34 & 3.17 & 1.56 & 6.45 \\
\hline & Month 18 & 0.46 & 0.16 & 1.36 & 1.37 & 0.43 & 4.40 & 1.09 & 0.36 & 3.32 & 0.86 & 0.40 & 1.87 & 0.68 & 0.23 & 2.01 & 2.24 & 1.08 & 4.65 \\
\hline
\end{tabular}



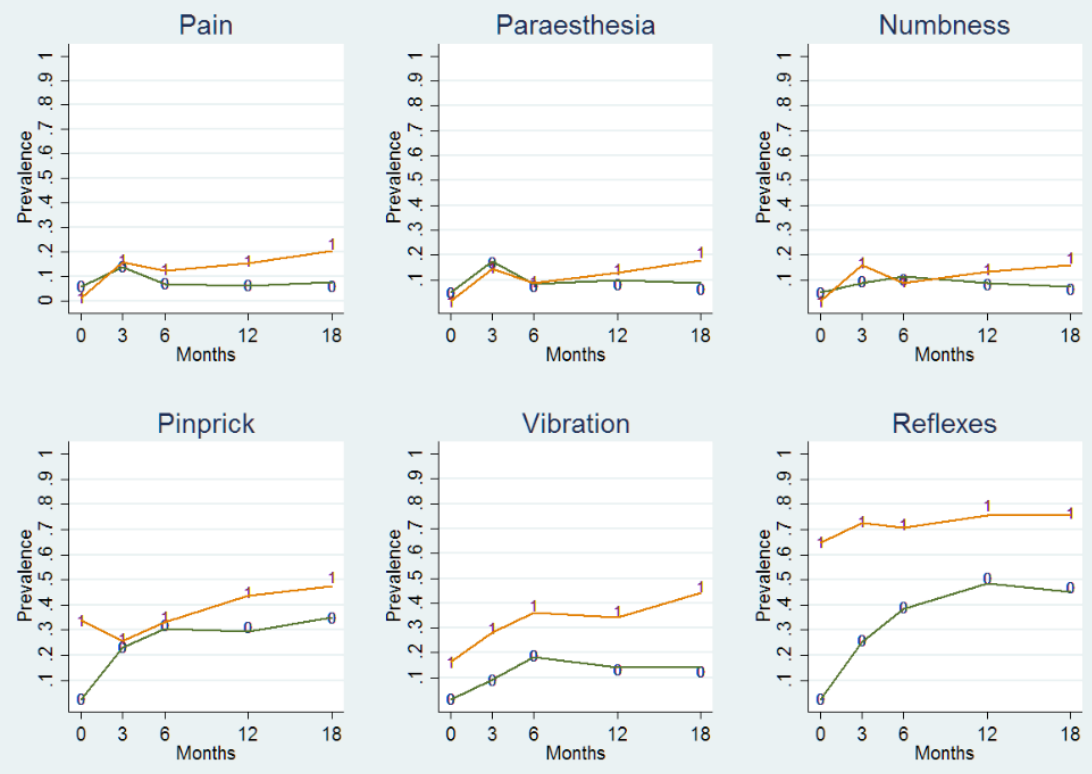

Supplementary Figure 1. Symptoms and signs at each visit in the group that entered the study with baseline (pre-ART) asymptomatic distal sensory polyneuropathy ("1") ( $n=73$ at baseline) vs. group that entered the study free of sensory neuropathy (" 0 ") ( $n=81$ at baseline).

In addition to the two models presented in the main text comparing prevalence of symptoms and signs at follow-up to baseline in and between groups, a third model compared the group that entered the study with ADSP vs. the group which was sensory neuropathy-free at study entry. However, the model could not be adequately fitted due to a lack of observations at baseline (no symptoms in the ASDP group, no signs in the neuropathy-free group). We therefore explored the model for trends without testing for statistical significance. 
9) Reviewers' comments and responses (Muscle \& Nerve) 
Review of MUS-16-0945

Reviewer 1: Comments to the Author

This paper reports on the evolution of PN following initiation of ART in Africa. Strengths of the study include standardized assessments of subjects using validated instruments, before and after initiation of different forms of ART. Notably there is a comparison of rates of PN in those receiving d4T, a neurotoxic agent, and tenofovir, without PN toxicity. Only minor issues deserve comment as follows:

1. Median baseline CD4 is 156 . This relatively advanced immunosuppressed cohort limits generalizability of these data to those initiating ART at higher CD4.

We added comment in discussion.

2. It is notable that there is a discordance between the evolution of symptoms and signs of DSP following ART, with or without use of d4T. While there is generally a reduction or no change in symptoms in many patients, there is an increase in signs. The authors might discuss implications of these findings.

Thank you for stressing this point. We have added a paragraph in the discussion.

3. The authors compare the evolution of PN in those that were SDSP positive or negative at baseline. The latter group presumably includes those that are PN-sign free and those with ADSP. It would be of interest to compare evolution of PN (onset of symptoms and/or onset or increase in signs) in those that are PN-sign free and those with ADSP at baseline.

We attempted this analysis but the model failed because of a lack of observations at baseline (e.g. no pain in the ADSP group at baseline). Instead, we have presented observed frequencies without modelling prevalence and without presenting any statistical analysis, and this is presented in supplementary material. However, we found a trend towards a greater increase in symptoms prevalence over time in the ADSP group when compared to the DSP-free group. When observing signs, there is a trend for an initial increase in signs then levelling off for the DSP-free group, while the increase in the ADSP group is more sustained. These findings suggest that ADSP before ART might increase the odds for symptoms later, although the survival analysis did not support this hypothesis. The ADSP group will also acquire new signs over time, while DSP-free participants will acquire signs primarily within the first 6 months.

We also experimented by inserting a "dummy" observation $(n=1)$ at baseline to force the model, and found that the model supported some of these trends. We present these data as supplementary figure and refer to it in the text.

\section{Reviewer 2: Comments to the Author}

Congratulation on job well done. While the HIV patients included in the study are relatively young which makes monoclonal paraproteinemia unlikely, did you consider testing pre ART symptomatic neuropathy patients for vitamin B12 deficiency especially that these patients have a predominantly sensory neuropathy and can have nutritional problems.

We agree that nutritional factors are an important component of the multifactorial pathogenesis of sensory neuropathy in this population. While low serum B12 levels $(<200)$ have been noted in $10 \%$ in a similar population, serum B12 is an unreliable test and low levels have a poor positive predictive value for true deficiency. Patients with symptomatic neuropathy were not routinely investigated for B12 deficiency in the clinic and we also did not measure B12 in this study. However, we have reviewed our data, and using the presence of macrocytic anemia as a surrogate marker of B12 deficiency, we have established that it is unlikely to be a major contributing factor. At baseline (pre-ART), 35\% had anemia ( $\mathrm{Hb}<12.4 \mathrm{~g} / \mathrm{dl}$ for men, $<10.6 \mathrm{~g} / \mathrm{dl}$ for women) and only 3 participants had macrocytic anemia (MCV <100). We did not do any further analysis but added comments in the results. 
Using less stringent criteria ( $\mathrm{Hb}<13 \mathrm{~g} / \mathrm{dl}$ for males, $<12 \mathrm{~g} / \mathrm{dl}$ for females), $38 \%$ had anemia and $6 \%$ had macrocytic anaemia (MCV <98.9). Using the less stringent criteria, macrocytic anemia was no more common in the symptomatic neuropathy group compared with the neuropathy-free group (6 vs $7 \%$ ). It is important to note that the HIV clinicians' society guidelines does not recommend the use of these less stringent criteria and particularly not at sea level (SAJHIVMED June 2012; 13; 87-104). We have not presented these data.

\section{Reviewer 3: Comments to the Author}

Study design

1. Definition of SDSP: Compared to the groups previous cross sectional study (Maritz et al. 2010) a less strict definition was used: instead of the presence of at least two neuropathic signs (reduced or absent reflexes, impaired vibration, or impaired pinprick), only one is required. An explanation why this was chosen, would be informative.

We used more stringent criteria in the former cross-sectional study to increase confidence in finding true neuropathy at a single time point (improved specificity). In this prospective study we were able to improve confidence in the finding by assessing signs from a known baseline, which improved specificity without having to use the stricter criteria. The relaxed criteria would also improve sensitivity.

We also aimed to improve generalizability/comparison of study findings, as most other studies use the less strict definition.

2. Measurement of symptoms: When patients were asked about neuropathic pain, were they asked about least, average or worst pain?

Worst pain. Have clarified in the text.

While measurement of pain intensity has been validated on a visual numerical rating scale (as cited in the text (Ferrar et al.)), has the measurement of numbness and paresthesia on this scale (and a 2 point decrease or increase on this scale as a significant change) been validated?

No, we extrapolated from the pain data. However, we also present the 'absolute' score changes in parallel for all modalities.

Would it be better to quantify patient reported numbness by location (up to ankle, up to foot, similar to quantifying exam findings) rather than on a numerical scale?

At your suggestion, we have explored symptomatic worsening/improvement by anatomical extent using the TNSr scale. It is worth noting that the TNSr captures only a single score for symptoms (be it pain, paresthesia and/or numbness). Using a 1-point change in TNSr to define worsening/improvement, we noted a trend similar to that seen for the 11-point numerical scale for each modality, namely that a large proportion of those ever experiencing symptoms will improve before or at their last follow-up (50.7\%) and a minority will worsen (10.7\%). These findings suggest that most patients experience a proximal regression in the anatomical extent of their symptoms, rather than a distal extension. We have presented these data in Table 4 and in the text.

3. Laboratory testing/nutritional deficiencies: It may have been informative to have other laboratory parameters included, which commonly can cause neuropathy in western populations, such as TSH and vitamin B 12, as nutritional deficiencies may play a role in this population, specifically B12 deficiency in HIV patients. 
We unfortunately did not capture these data. However, for B12, please see our response above (reviewer 2).

4. Assessment of vitamin use or neurotoxic medications - B6/Tb treatment: Was it assessed whether patients were taking $\mathrm{B} 6$ during current or previous Tb treatment?

We did record these data for current usage; however, a very low proportion $(n=2)$ reported using B6. Have added text.

\section{Was it assessed whether patient were exposed to other neurotoxic medications such as metronidazole?}

Folder reviews were completed and we did attempt to capture all concomitant medications. We have added this in the discussion

\section{How was alcohol use defined?}

We used a single question screen that defined alcohol use as any intake during the preceding 1-year period similar to our previous cross-sectional study by Maritz et al. (2010) in which we also did not find alcohol to be a risk factor. We concede that the definition is probably over-inclusive; however, defining the pattern of use conferring neurotoxic potential is also challenging. Even with these relaxed criteria, only $29 \%$ reported alcohol use in the preceding 1-year period. (This may reflect cultural aspects of the primary demographic).

6. Triglycerides seem to play a role in pre-ART SDSP. Would it have been better to measure hip waist ratio (as in the previous study 2010 ) rather than $\mathrm{BMI}$ to assess for metabolic syndrome, which in conjunction with elevated Triglycerides can cause neuropathy? (In previous study BMI was not significantly correlated with neuropathy while the hip waist ratio was). Is it possible that ART increased triglycerides levels at follow up equally in all patients and therefore evened out the effect of elevated triglycerides in SDSP patients pre-ART, which at the time may have been due to co-existing metabolic syndrome?

Thank you for this comment. We have included the hip-waist ratio in the table comparing baseline and 24 month clinical and laboratory findings (we also combined the previously seperate 12- and 24-month tables). In the univariate analysis at baseline there was a trend towards an association between SDSP and hip-waist ratio, but not for ADSP. Neither showed the association at 24 months. In our previous cross-sectional cohort we found similar associations with hip-waist ratio as well as triglycerides and preART DSP but not in a cross-sectional cohort exposed to ART for a median of 14 months. Although the reviewer's hypothesis is intriguing, we have decided that without enough evidence to suggest any postulates we would only highlight these observations when discussing the evolution of two neuropathy phenotypes over time.

7. CD4 counts were assessed at baseline and 24 weeks follow up. I assume treatment effect/adherence/developing resistance beyond 6 months follow up is unknown/not assessed.

We did not collect specific data regarding treatment failure or success past 24 weeks.

Study population

8. Duration of enrollment (years) would be informative.

A 1.5-year period. We have added to the text. 
9. There was marked loss of follow up of $12 \%$ per visit with only $50 \%$ assessed at the study endpoint. Is this typical for this study population (acknowledging that the patients staying in the study and dropping out did not differ in their demographics)?

Some degree of loss-to-follow-up is not atypical in this study population, primarily because of socioeconomic factors that drive migration and at times limit access to healthcare. We acknowledge that these factors may have introduced bias. Have added text.

Results

10. Was the patient's medication list reviewed which may have included medications for neuropathic pain. As a result, use of these medications may explain improvement of pain and paresthesia in the preART SDSP group after ART initiation, while numbness and physical exam findings did not change. (Although I am aware that as stated in previous publication of the group, HIV neuropathy pain responds less to commonly used medications and patients are less frequently treated symptomatically in this population).

We collected these data, which revealed that a low proportion received therapy for pain, mainly amitriptyline: less than $30 \%$ for most visits and $50 \%$ at the final visit. We have added text to limitations but also added that is unlikely to impact on our assessments as amitriptyline is not a useful therapy for HIV neuropathy as mentioned.

11. Improvement of pre-ART SDSP after ART initiation: pain and paresthesia sustainably improved after ART initiation, with improvement of pinprick examination at 3 months (although this is not a sustained improvement). Vibration sensation, numbness and reflexes did not improve. Could this suggest improvement of small fiber qualities rather than large fibers?

We did four longitudinal analyses:

1) Incidence rate of new SDSP

2) Survival analysis comparing risk factors for new SDSP

3) Mean score difference between first occurrence of the abnormality till last follow-up

4) Prevalence of symptoms and signs at each visit, comparing prevalence at baseline to prevalence at follow-up in groups and between groups (pre-ART SDSP vs. pre-ART SDSP-free, stavudine vs. no stavudine)

In analysis 3, pain and paresthesia improved in 50\% ever experiencing symptoms, irrespective of DSP status.

In analysis 4, after ART initiation the prevalence of pain and paresthesia decreased in those with pre-ART SDSP but without 'sustained' improvement in pinprick after 3 months (supplementary fig 4) making it difficult to draw a conclusion about small fibers. However, we have expanded the discussion regarding the emergence of differences in neuropathic phenotypes at different times within the 2 year period.

Also, the data suggests that after 18 months of ART, those with SDSP at baseline were not at increased risk of developing signs or symptoms compared to those without SDSP at baseline suggesting that the early pathogenic process may not be adding to cumulative risk.

12. Figure 1 compares symptoms and signs of patients with SDSP and SDSP-free patients. Patients with ADSP are included in the SDSP-free group. If the SDSP-free group is separated into ADSP and neuropathy-free groups, does the effect sustain? Or would this show that patients with ASDP only are predisposed to develop worsening of symptoms after ART initiation? This way one could conclude from this study that ASDP is a risk factor for new onset of DSDP on ART? 
In our survival analysis, we did not find ADSP at baseline to be a significant risk factor for the development of SDSP. For the analysis you have suggested, please see comments above.

The model for baseline ADSP vs. DSP-free (normal) could not be adequately fitted due to a lack of observations at baseline (no symptoms in the ASDP group, no signs in the DSP-free group). We substituted a set of dummy observations at baseline which enabled the model to be fitted but resulted in inconsistent results and wide confidence intervals for associations. We examined the model for trends instead. A greater proportion of those participants with baseline ADSP had painful symptoms at followup visits when compared to baseline DSP-free participants. This difference appeared less prominent for the other symptoms. We did not see ADSP at baseline as a predictor for the development of SDSP on survival analysis. Signs increased in both groups, but differing profiles were observed for reflexes in the two groups.

\section{Associate Editor}

Comments to Author:

1. Please proofread the document and edit for consistency in either British or American English. As pointed out by a reviewer, the text currently mixes both variants. The journal defaults typically defaults to American English.

We have attended to these.

2. Please address the reviewers' comments and questions. Of particular interest, the discussion should address possible differences between small and large nerve fiber response to ART.

Please see above

\section{Editor-in-Chief}

Comments to Author:

Results

--Please do not redundantly repeat numbers and percentages in the Results that are provided in the tables. Use Results to highlight important points, and then refer the reader to the Tables for specific data when appropriate.

Please see changes in the text. We have retained a few data points in the text particularly from supplementary tables.

--Table 1 is rather lengthy, and broad, and thus will be hard for readers to sort through. Can you remove those pieces of data that are not critical to your paper? For example, is it critical for the reader to know weight, height, BMI, blood pressure, and cholesterol? Readers do not need all data, but simply the most relevant data. If you feel you must list all this data, consider moving some to a supplementary table, available on-line. Same concerns about Table 3.

Please see revised Table 1 and 3 and new supplementary tables 1 and 2. 
10) Editorial and issue highlights (Muscle \& Nerve) 


\title{
HIV, ANTIRETROVIRALS, AND PERIPHERAL NEUROPATHY: A MOVING TARGET
}

\author{
MICHELLE KAKU, MD, ${ }^{1}$ and DAVID M. SIMPSON, MD ${ }^{2}$ \\ ${ }^{1}$ Boston University School of Medicine, Department of Neurology, Boston, Massachusetts, USA \\ ${ }^{2}$ Icahn School of Medicine at Mount Sinai, Department of Neurology, New York, New York, USA
}

HIV-distal symmetric polyneuropathy (HIV-DSP) is the most common neurologic complication of HIV disease in the post-antiretroviral therapy (ART) period. There are limited regenerative or symptomatic treatment options for HIV-DSP, and currently no Food and Drug Administration-approved therapies exist. Of the ART therapies, dideoxynucleoside analogue ARTs or "d-drugs" such as stavudine, didanosine, and zalcitabine are often vilified in the HIV-DSP literature. They are known to cause or exacerbate neuropathy in the HIV population and can lead to antiretroviral toxic neuropathy (HIV-ATN) ${ }^{1-4}$ A previous cross-sectional study of HIV-infected South Africans found that the frequency of symptomatic HIV-DSP increased from $23 \%$ to $40 \%$ following ART exposure. ${ }^{5}$

HIV-DSP and HIV-ATN cannot easily be differentiated clinically or electrophysiologically; development of neuropathy symptoms after initiation of ART may be the only distinguishing factor. Pathophysiologically, it is thought that HIV causes neuropathy directly by the dysregulation of macrophages, release of pro-inflammatory cytokines, chemokines and free radicals, ${ }^{6}$ systemic and cerebrospinal fluid (CSF) immune activation, ${ }^{7}$ and neurotoxicity of the gp120 envelope protein. ${ }^{8}$ In contrast, "d-drug" toxicity is thought to arise from mitochondrial toxicity caused by inhibition of gamma DNA polymerase and reduced mitochondrial DNA content. ${ }^{9}$ While "ddrugs" have been largely replaced in developed countries, they are still used in developing countries and resource-limited settings. It remains critical to understand the true impact of "d-drugs" versus other ARTs, the time course of development of HIV-ATN and the various contributing and potentially modifiable risk factors for HIV-ATN in this population, given the prevalence, the limited effective symptomatic therapies, and the impact on quality of life.

Correspondence to: M. Kaku; email: mikaku@bu.edu

Conflicts of Interest: None of the authors has any relevant conflict of interest to disclose.

(C) 2017 Wiley Periodicals, Inc.

Published online 20 October 2017 in Wiley Online Library (wileyonlinelibrary. com). DOI 10.1002/mus.25990
In their prospective study that appears in this issue of Muscle $\mathcal{E}$ Nerve, Centner and colleagues studied the evolution of sensory neuropathy after initiation of ART therapy in HIV-infected South Africans. ${ }^{10}$ The study follows patients at 6-monthly follow up visits for a 24-month period, beginning before they start. Major confounders such as pre-existing diabetes, systemic illness and other comorbid neurological disease were excluded. They defined symptomatic distal sensory polyneuropathy (SDSP) as the presence of $\geq 1$ sensory symptom (pain, paresthesias, or numbness) with $\geq 1$ neuropathic sign (reduced pinprick sensation, or reduced/absent reflexes) and asymptomatic distal sensory polyneuropathy (ADSP) as the presence of $\geq 1$ neuropathic sign in the absence of sensory symptoms. Incident SDSP was defined as asymptomatic at baseline with development of SDSP after ART initiation. The authors applied validated tools (Brief Peripheral Neuropathy Screen and a reduced version of the Total Neuropathy Score) to assess neuropathy symptoms and signs.

Of the 184 participants, $16 \%$ had SDSP and 39\% had ADSP pre-ART, demonstrating the considerable prevalence of neuropathy in this population. PreART SDSP was associated with age, waist:hip ratio, previous and current TB treatment and higher triglyceride levels. Risk factors independently associated with baseline SDSP were previous or current TB treatment and higher triglyceride levels. After 18 months of ART therapy, they found that the prevalence of pain symptoms decreased at each follow-up visit in the baseline SDSP group (odds ratio $[\mathrm{OR}]=0.09 ; 95 \%$ confidence interval $[\mathrm{CI}], 0.03-$ $0.29)$, while symptom prevalence increased in the SDSP-free group. The prevalence of signs increased in the overall cohort at each visit. Participants who were SDSP-free pre-ART developed incident SDSP at a rate of 18 per 100 person-years; after 24 months $(n=102), 18 \%$ had SDSP. In the analysis of participants receiving stavudine versus a non-stavudine ART, the researchers found that stavudine did not predict incident SDSP, but was associated with increased prevalence of reduced/absent reflexes at 18 months. 
This study provides a unique opportunity to prospectively and longitudinally assess participants using standardized methods with baseline analyses before and after initiation of different forms of ART treatment. Despite the potential risk of developing HIV-ATN, the present study suggests that the symptomatic benefits of early initiation of ART initiation (whether "d-drug" or not) outweigh the risk of causing significant symptoms, as the use of stavudine did not significantly predict onset of SDSP. Additionally, the study occurred during the government initiated phase-out of stavudine and the introduction of tenofovir-containing ART treatments in South Africa. Participants who received stavudine had a higher baseline prevalence of pain and lower CD4 + cells counts compared with those who were started on a non-stavudine containing regimen. Despite this, symptom prevalence was not significantly different between the two groups after treatment initiation. Both groups had an increasing prevalence of signs but the increase in prevalence for impaired vibration sensation was significantly greater in the stavudine group at months 6,12 , and $18(\mathrm{OR}=2.24 ; 95 \% \mathrm{CI}, 1.08-4.65$ for stavudine versus non-stavudine at 18 months).

The discrepancy between increasing signs of DSP despite decreasing symptoms seen in the overall cohort has similarly been demonstrated in a large cross sectional study of 2,141 HIV-DSP participants followed over 7 years, which found that signs remained in the absence of symptoms despite virologic and immunologic control with initiation of combination ARTs. ${ }^{11}$ Previous studies have demonstrated that markers of systemic and CSF immune activation are elevated in patients with ART-naive HIV-DSP compared with HIV patients without neuropathy. ${ }^{7}$ Centner and colleagues suggest that viral clearance and immune stabilization lead to a reduction in painful small-fiber symptoms seen in participants with pre-existing HIV-associated SDSP after ART initiation.

The worsening of clinical signs may be due to slow transport of dysfunctional mitochondria down axons over months to years and the susceptibility of distal sensory axons to mitochondrial defects. This phenomenon warrants further study; the acquisition of follow up data on the current cohort would be interesting as a way of determining whether this trend continues.

Additionally, the authors compare the evolution of neuropathy in those that were SDSP positive or negative at baseline. The latter group presumably includes those that are neuropathy sign-free and those with ADSP. It would be of interest to compare evolution of neuropathy (onset of symptoms and/or onset or increase in signs) in those that are neuropathy-sign free and those with ADSP at baseline.

Consistent with previous studies, the authors found that the first 3-6 months after ART initiation was associated with the highest risk of developing SDSP. ${ }^{12}$ Participants in this study were mostly women, with a median age of $33.38 \%$ had a history of previous or current TB treatment, and median baseline CD4 count was 156 . While this CD4 count may reflect populations in South Africa, ${ }^{13}$ this relatively advanced immunosuppressed cohort may limit generalizability of the data to those initiating ART with a higher CD4 count.

Previously identified risk factors associated with post-ART HIV-DSP include greater age, ${ }^{11}$ greater height, ${ }^{4,11}$ history of protease inhibitor use, ${ }^{11}$ history of statin and fibrate use, ${ }^{14,15}$ diabetes, ${ }^{11}$ and hypertriglyceridemia. ${ }^{15}$ In the present study, incident SDSP after ART initiation was associated with age $\geq 40$ years (hazard ratio $[\mathrm{HR}]=3.0 ; 95 \% \mathrm{CI}$, 1.5-6.1) and inversely associated with fasting insulin levels (HR $=0.8 ; 95 \%$ CI, 0.6-1.0).

On multivariate analysis, the association with fasting insulin remained significant (adjusted $\mathrm{HR}=0.8 ; 95 \% \mathrm{CI}, 0.6-1.0)$, but the association with age did not. Older age is thought to increase the vulnerability of peripheral nerves, although the younger cohort in this study may have impacted the results. Despite the exclusion of diabetics from the study, the inverse association with fasting insulin reinforces the link between glucose intolerance in the HIV population and neuropathy risk. Fasting triglyceride levels were associated with SDSP in the baseline pre-ART cohort, but were not associated with SDSP at the end of 24 months.

Previous data suggests that hyper-triglyceridemia and diabetes, although not necessarily metabolic syndrome or its components, are associated with SDSP. ${ }^{16}$ The authors suggest that the absolute triglyceride level itself may not be critical, but may be a biomarker for painful neuropathy. In contrast to studies in developed countries where statin use is prevalent, this study also had the unique opportunity to assess triglyceride levels in participants not on statins. Statins are a potential confounder that are an independent risk factor for HIV-DSP ${ }^{15}$ and whose use may decrease the chance of recovery from symptomatic neuropathy. ${ }^{11}$

This prospective study demonstrates the trajectory of neurologic signs and symptoms in a young predominantly female African population with relatively advanced HIV infection, treated with different ART therapies. Symptomatic neuropathic pain mostly improved with ART initiation in the setting of increasing prevalence of neuropathic signs, while only a small proportion of the studied population developed painful neuropathic symptoms. 
They seem to suggest that initiating ART early, whether "d-drug" containing regimen or not, appears to be beneficial from a symptomatic stand point, particularly if there is no alternative option. However, in a period where government sponsored programs are eliminating "d-drugs" in favor of other ART drugs, the findings raise the question of whether one should take this risk if and when other options are available. As the rapid pace of development and introduction of novel ART continues, it is critical that neurological benefits and toxicities be carefully monitored for both the central and peripheral nervous systems.

Ethical Publication Statement: We confirm that we have read the Journal's position on issues involved in ethical publication and affirm that this report is consistent with those guidelines.

\section{REFERENCES}

1. Ellis RJ, Rosario D, Clifford DB, McArthur JC, Simpson D, Alexander $\mathrm{T}$, et al. Continued high prevalence and adverse clinical impact of human immunodeficiency virus-associated sensory neuropathy in the era of combination antiretroviral therapy: the CHARTER Study. Arch Neurol 2010;67:552-558

2. Browne MJ, Mayer KH, Chafee SB, Dudley MN, Posner MR, Steinberg SM, et al. 2', 3'-didehydro-3'-deoxythymidine (d4T) in patients with AIDS or AIDS-related complex: a phase I trial. J Infect Dis 1993;167:21-29.

3. Smyth K, Affandi JS, McArthur JC, Bowtell-Harris C, Mijch AM, Watson K, et al. Prevalence of and risk factors for HIV-associated neuropathy in Melbourne, Australia 1993-2006. HIV Med 2007;8: 367-373.

4. Cherry C, Affandi J, Imran D, Yunihastuti E, Smyth K, Vanar S, et al. Age and height predict neuropathy risk in patients with HIV prescribed stavudine. Neurology 2009;73:315-320.
5. Maritz J, Benatar M, Dave JA, Harrison TB, Badri M, Levitt NS, et al. HIV neuropathy in South Africans: frequency, characteristics, and risk factors. Muscle Nerve 2010;41:599-606.

6. Hao S. The molecular and pharmacological mechanisms of HIVrelated neuropathic pain. Curr Neuropharmacol 2013;11:499-512.

7. Wang SXY, Ho EL, Grill M, Lee E, Peterson J, Robertson K, et al. Peripheral neuropathy in primary HIV infection associates with systemic and CNS immune activation. J Acquir Immune Defic Syndr 2014;66:303-310.

8. Keswani SC, Polley M, Pardo CA, Griffin JW, McArthur JC, Hoke A. Schwann cell chemokine receptors mediate HIV-1 gp120 toxicity to sensory neurons. Ann Neurol 2003;54:287-296.

9. Brinkman K, ter Hofstede HJ, Burger DM, Smeitink JA, Koopmans PP. Adverse effects of reverse transcriptase inhibitors: mitochondrial toxicity as common pathway. Aids 1998;12:1735-1744.

10. Centner CM, Little F, van der Watt JJ, Vermaak JR, Dave JA, Levitt NS, et al. Evolution of sensory neuropathy after initiation of antiretroviral therapy. Muscle Nerve 2017. [Epub ahead of print].

11. Evans SR, Ellis RJ, Chen H, Yeh TM, Lee AJ, Schifitto G, et al. Peripheral neuropathy in HIV: prevalence and risk factors. AIDS 2011;25:919-928.

12. Arenas-Pinto A, Bhaskaran K, Dunn D, Weller I. The risk of developing peripheral neuropathy induced by nucleoside reverse transcriptase inhibitors decreases over time: evidence from the Delta trial. Antivir Ther 2008;13:289.

13. Siedner MJ, Ng CK, Bassett IV, Katz IT, Bangsberg DR, Tsai AC. Trends in CD4 count at presentation to care and treatment initiation in sub-Saharan Africa, 2002-2013: a meta-analysis. Clin Infect Dis 2015;60:1120-1127.

14. Corrao G, Zambon A, Bertù L, Botteri E, Leoni O, Contiero P. Lipid lowering drugs prescription and the risk of peripheral neuropathy: an exploratory case-control study using automated databases. J Epidemiol Community Health 2004;58:1047-1051.

15. Banerjee S, McCutchan JA, Ances BM, Deutsch R, Riggs PK, Way L, et al. Hypertriglyceridemia in combination antiretroviral-treated HIVpositive individuals: potential impact on HIV sensory polyneuropathy. AIDS 2011;25:F1-F6.

16. Ances BM, Vaida F, Rosario D, Marquie-Beck J, Ellis RJ, Simpson $\mathrm{DM}$, et al. Role of metabolic syndrome components in HIV associated sensory neuropathy. AIDS 2009;23:2317-2322. 


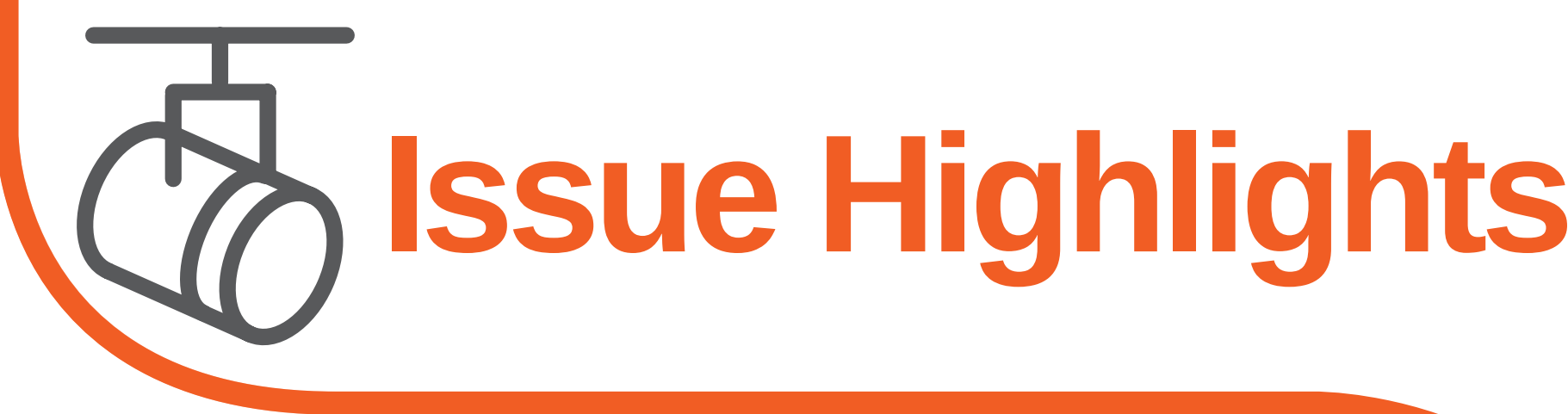

\section{Evolution of Sensory Neuropathy after Initiation of Antiretroviral Therapy (Page 371)}

Individuals infected with human immunodeficiency virus (HIV) may develop a distal sensory polyneuropathy. The authors of this study found that patients with such neuropathies had an improvement in painful symptoms when treated with anti-retroviral therapy (ART), but that some of those who were neuropathy-free prior to ART developed new painful neuropathic symptoms. The accompanying editorial by Drs. Kaku and Simpson provides expert perspective for the clinician in the interpretation of these findings.

\section{Chronic Pain Has a Strong Impact on Quality of Life in Facioscapulohumeral Muscular Dystrophy (Page 380)}

As is true for many neuromuscular disorders, pain is common in facioscapulohumeral muscular dystrophy (FSHD). This study confirmed the common occurrence of pain in FSHD, finding that nearly $90 \%$ of individuals with FSHD reported pain during the study, more than half reported chronic pain, and nearly a third reported chronic, severe pain. Chronic pain had a negative impact on multiple domains of quality of life (QOL). Because symptom management is the primary goal of care in patients with FSHD, clinicians should be sensitive to the need for adequate treatment of pain as one means of optimizing QOL for these individuals.

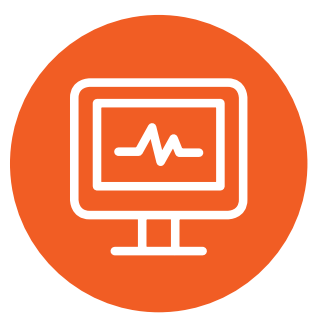

\section{Carpal Tunnel Syndrome in Inherited Neuropathies: A Retrospective Survey (Page 388)}

Inherited neuropathies are a heterogeneous group of disorders that are commonly seen by neuromuscular specialists. Carpal tunnel syndrome (CTS) is the most common entrapment neuropathy. Yet, optimal methods for the evaluation and management of CTS in patients with inherited neuropathies have not been defined. The authors of this study present data to fill some of these gaps. In this study of patients with CTS and inherited neuropathies, CTS was found to be reported at a higher rate than in the general population, and the CTS symptom severity score (SSS) was found to be useful for assessing their CTS. Splinting and surgery were both found to be associated with significant symptom reduction in these patients as measured by the SSS.

\section{Recovery of Rat Muscle Size But Not Function More Than 1 Year After a Single Botulinum Toxin Injection (Page 435)}

Botulinum toxin is being used with increasing frequency and for longer periods of time in the treatment of patients with a wide variety of neuromuscular disorders. In this study, the authors found that rats injected with botulinum toxin type A demonstrated persistent muscle weakness a year after injection, despite recovery of muscle fiber size and mass. In an accompanying editorial, Dr. Ib Odderson notes that the results of this animal study do not seem to parallel the experience of clinicians, who often administer botulinum toxin every 3 months to maintain weakness in spastic muscles. He and the authors of the article discuss possible explanations.

\section{Ventilator-Induced Diaphragmatic Dysfunction in MDX Mice (Page 442)}

Patients with Duchenne Muscular Dystrophy (DMD) and some other neuromuscular disorders often are treated with intermittent mechanical ventilation, particularly at night. The implications of such treatment for diaphragm strength are not understood. Using an animal model of DMD, the authors of this study found that diaphragm force loss and biochemical changes in the diaphragm occurred rapidly in response to mechanical ventilation. Drs. Smith and Falk, in an accompanying editorial, highlight important differences between humans with DMD and MDX mice. They outline the tremendous benefits of noninvasive ventilation and some points that require clarification in order to optimize its use.

\section{Feasibility of 7T MRI for Imaging Fascicular Structures of Peripheral Nerves (Page 494)}

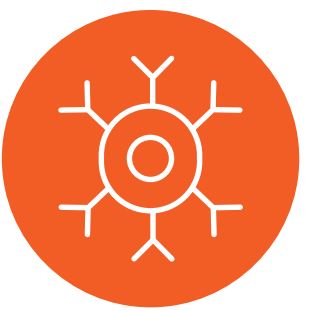

High resolution imaging of peripheral nerves has been critical in framing our thinking about pathophysiology. For example, some peripheral nerve lesions that have traditionally been considered compressive, such as posterior and anterior interosseous syndromes, appear to arise from processes selectively affecting nerve fascicles. This study by Yoon and colleagues features images obtained by 7T MRI that are striking in their clarity and detail when compared to conventional 3T MRI studies. Such imaging has the potential to transform the diagnosis of peripheral nerve disorders. 
11) Data capture instruments 


\section{SA BRIEF PERIPHERAL NEUROPATHY SCREENING/EXAM (UCT REC 221/2008)}

\begin{tabular}{|c|c|c|c|c|c|c|}
\hline NO: & $\mathbf{T}$ & BASELINE & Date: & $d d$ & $\mathrm{~mm}$ & yy \\
\hline
\end{tabular}

We are going to ask you a few questions about sensation in your legs. We will also briefly examine the nerves in your arms and legs. We may advise the clinic doctor on treatment.

BPNS : INSTRUCTIONS FOR RECORDING SYMPTOMS: Ask subject to rate the severity of each symptom in 1a to $1 \mathrm{c}$ on a scale of 0 (absent) to 10 (most severe) for right and left feet, legs- worst in last week. Enter the score for each symptom in the block marked Severity. Enter extent of symptoms eg Soles of feet/ toes (TNS=1); up to ankle (TNS=2); up to knee $(\mathrm{TNS}=3)$ or above $(\mathrm{TNS}=4)$ on the TNS score overleaf.

1a. Pain, aching, burning in feet or legs. Ingaba iinyawo zakho zibuhlungu, ziyaqagamba, ziyatshisa kangangee-veki ezimbini?

\begin{tabular}{|l|l|l|l|l|l|l|l|l|l|l|}
\hline Normal & Mild & $\rightarrow$ & $\rightarrow$ & & & & & & & Severe \\
\hline 0 & 1 & 2 & 3 & 4 & 5 & 6 & 7 & 8 & 9 & 10 \\
\hline Andinantlungu! $\rightarrow$ & $\rightarrow$
\end{tabular}

\begin{tabular}{|l|l|}
\hline Nn1 & \\
score 1a &
\end{tabular}

1b. "Pins-and-Needles" in feet or legs. Ingaba iinhawo zakho zineenaliti noonotaka kangangee-veki ezimbini?

\begin{tabular}{|c|c|c|c|c|c|c|c|c|c|c|}
\hline Normal & Mild & $\rightarrow$ & $\rightarrow$ & $\rightarrow$ & $\rightarrow$ & $\rightarrow$ & $\rightarrow$ & $\rightarrow$ & $\rightarrow$ & Severe \\
\hline 0 & 1 & 2 & 3 & 4 & 5 & 6 & 7 & 8 & 9 & 10 \\
\hline
\end{tabular}

Nn2

1c. Numbness (lack of feeling) in feet or legs. Ingaba inyawo zakho zinobundindisholo kangangee-veki ezimbini?

\begin{tabular}{|l|l|l|l|l|l|l|l|l|l|l|}
\hline Normal & Mild & $\rightarrow$ & $\rightarrow$ & & & & & & & Severe \\
\hline $\mathbf{0}$ & 1 & 2 & 3 & 4 & 5 & 6 & 7 & 8 & 9 & 10 \\
\hline Andinantlungu! $\rightarrow$ & $\rightarrow$
\end{tabular}

Nn3

TOTAL SENSORY PRESENCE/SEVERITY SCORE: Obtain the single highest severity score from 1-10 in 1(a - c) above:
0 = Grade 0
1-3 = Grade 1
4- 6 = Grade 2
7-8 = Grade 3
9-10 = Grade 4

Total sensory severity GRADE

1d. Does the patient experience leg cramps?

Yes (1)

No $(0)$

$\mathrm{nn} 5$

Patient asymptomatic $(1 \mathrm{a}, \mathrm{b}, \mathrm{c}=\mathbf{0})$

1e. Has patient had any symptoms in the past which are not currently present?

Yes (1)

No $(0)$

$\mathrm{nn} 6$

\section{Patient symptomatic}

1f. Approximately when did the symptoms start?

Before TB Rx (1) After TB Rx (2)

1g. If symptoms started before TB Rx, then how have the symptoms responded to TB treatment?

$$
\text { Much Worse (1) Worse (2) }
$$

1h. Have you taken anything for the symptoms?

1i. If yes, what? nn11 How have the symptoms responded?

Much Worse (1)

Worse (2)

No change

(3) Better (4)

Much Better (5) 
Revision V3 March 2010

\section{INSTRUCTIONS FOR EVALUATING PERCEPTION OF VIBRATION:}

Press the 2 ends together of a $128 \mathrm{~Hz}$ tuning fork, and release suddenly; place the vibrating tuning fork on the subject's clavicle; can they recognise the vibration or "buzzing" (ngcungcazela) of the tuning fork? Repeat and immediately place the vibrating tuning fork firmly on the interphalangeal bone (not nail) of one great toe and begin counting the seconds. Subject to tell you when the "buzzing" stops. Repeat on the other side.

\section{Vibration Perception}

(Take highest score but both $\mathrm{R} \& \mathrm{~L}$ must be abnormal)
0 - Vibration felt for $>10$ seconds (normal)

1- Vibration felt for 6-10 seconds (mild loss)

2- Vibration felt for 5 seconds or less (moderate loss)

3- No feeling of vibration (severe loss)
Great toe interphalangeal bone
Left
(2) use highest value $/ 3$ nn11

\section{INSTRUCTIONS FOR EVALUATING DEEP TENDON REFLEXES:}

With the subject seated, the examiner uses one hand to press upward on the ball of the foot, dorsiflexing the subject's ankle to 90 degrees. Using a reflex hammer (long-handled), the examiner strikes the Achilles tendon.

$\begin{array}{lll}\text { Reflexes } & 4- & \text { Absent } \\ & 3- & \text { Reduced (difficult to elicit) } \\ 2- & \text { Normal deep tendon reflexes } \\ 1- & \text { Hyperactive deep tendon reflexes } \\ 0- & \text { Clonus }\end{array}$
Ankle Reflexes:
Right
Left
(Take highest score but both $R \& L$ must be abnormal)
(3) use highest value
nn12

Final score for BPNS (1+2+3)

Reduced TNS score: tick in the box :

\begin{tabular}{|c|c|c|c|c|c|c|}
\hline & 0 & 1 & 2 & 3 & 4 & \\
\hline $\begin{array}{l}\text { a. Sensory symptoms } \\
\text { from 1a,b,c: Pain, } \\
\text { burning pins or numbness }\end{array}$ & none & $\begin{array}{l}\text { Only in toes or } \\
\text { soles of feet }\end{array}$ & $\begin{array}{l}\text { Symptoms extend to } \\
\text { ankle or wrist }\end{array}$ & $\begin{array}{l}\text { Symptoms extend to } \\
\text { knee or elbow }\end{array}$ & $\begin{array}{l}\text { Symptoms knee or } \\
\text { elbow or functionally } \\
\text { disabling }\end{array}$ & $\mathrm{nn} 14$ \\
\hline b. Pin sensibility & normal & $\begin{array}{l}\text { Reduced in fingers } \\
\text { /toes }\end{array}$ & $\begin{array}{l}\text { Reduced up to wrist/ } \\
\text { ankles }\end{array}$ & $\begin{array}{l}\text { Reduced up to elbow/ } \\
\text { knee }\end{array}$ & $\begin{array}{l}\text { Reduced above } \\
\text { elbow/ knee }\end{array}$ & nn15 \\
\hline $\begin{array}{l}\text { c. Vibration sensibility } \\
\text { (use normal as for BPNS) }\end{array}$ & normal & $\begin{array}{l}\text { Reduced in fingers } \\
\text { /toes }\end{array}$ & $\begin{array}{l}\text { Reduced up to wrist/ } \\
\text { ankles }\end{array}$ & $\begin{array}{l}\text { Reduced up to elbow/ } \\
\text { knee }\end{array}$ & $\begin{array}{l}\text { Reduced above } \\
\text { elbow/ knee }\end{array}$ & nn16 \\
\hline d. Deep tendon jerks & normal & $\begin{array}{l}\text { Ankle reflexes } \\
\text { reduced }\end{array}$ & Ankle reflexes absent & $\begin{array}{l}\text { Ankle reflexes absent, } \\
\text { other reduced }\end{array}$ & All reflexes absent & $\mathrm{nn} 17$ \\
\hline $\begin{array}{l}\text { e. Strength- ankle and } \\
\text { toes plantar \& dorsi- } \\
\text { flexion }\end{array}$ & normal & $\begin{array}{l}\text { Mild weakness } \\
\text { (MRC 4) }\end{array}$ & $\begin{array}{l}\text { Moderate weakness } \\
\text { (MRC 3) }\end{array}$ & $\begin{array}{l}\text { Severe weakness } \\
\text { (MRC2) }\end{array}$ & $\begin{array}{l}\text { Paralysis } \\
\text { (MRC 0-1) }\end{array}$ & nn18 \\
\hline
\end{tabular}

Neuropathy classification according to TNS:

Symptomatic $D S P=a \geq 1$ and $b \geq 1$ or $c \geq 1$ or $d \geq 1$ or significant touch-evoked pain

Asymptomatic DSP $=$ TNS $\geq 3$

yes/ no

Indeterminate $\mathrm{DSP}=\mathrm{a} \geq 1$ only

yes/ no

$\mathrm{nn} 21$

yes/ no

Punch Biopsy performed

yes/ no

Examination shows another form of peripheral neuropathy (not symmetric distal sensory) yes/no

refer for further evaluation to neuromuscular HIV clinic at GSH (1st wed am of every month; 404-3209) 
UCT ICD modified Dec 09

\title{
Patient Information Sheet for the McHaart \& Neuropathy Study
}

\section{Title: Prevalence of HIV Neuropathy and risk factors for antiretroviral toxic neuropathy in an HIV positive cohort of Black South Africans.}

\author{
Dr J Dave (Endocrinology), A/Prof J Heckmann (Neurology); University of Cape Town
}

You are invited to participate in a research project at Groote Schuur Hospital.

Before you agree to take part you need to understand the following:

Many HIV-positive patients around the world are treated with a combination of special medications to try and stop the HIV from dividing in the cells of the body and causing harm. These mediations are called highly active antiretroviral therapy or HAART for short. Although HAART cannot cure HIV/AIDS (i.e., some virus still stays in the cells) it has helped to fight the development of AIDS and has helped and saved a lot of patients. However, HAART has to be taken for the rest of the person's life and it has side-effects. Some of these side-effects have included the development of diabetes, cholesterol problems, changes in body shape (usually either more or less fat in certain areas of the body) and may also damage the nerves in the feet causing pain. Very little is known about these problems in the HIV-patients in South Africa. In this study we want to monitor the effects of HAART in patients in Cape Town and especially in the first year of starting HAART. This would help the doctors and patients to understand the side-effects of HAART, how commonly they occur, and how they can best be treated or even prevented. Not everyone will develop problems on HAART but it will be very useful if we can understand who will develop problems so that we can try alternative treatment plans.

One of the possible complications of HIV infection could be damage to the long nerves supplying the skin of the feet and legs causing most commonly pain and tingling in the feet. This problem is called peripheral neuropathy. Unfortunately, it may also be a side effect of HAART (also known as ARVs - anti-retrovirals). Although HAART/ARVs is useful in treating $\mathrm{HIV}$, it may also cause or worsen peripheral neuropathy in some patients and very little is known about this problem in South African patients. In this study we also want to learn more about why some patients with HIV and those taking HAART/ARVs develop painful feet, and how treatment for TB and vitamin levels in the body (vitamin B6 especially) can contribute to this problem. This will help us to develop ways to prevent or treat this side effect of HAART/ARVs.

We want to study the vitamin B6 levels in the blood and see whether you have enough for your body's needs. We also want to take blood for a genetic test called NAT2 which we think, may tell us whether a person's body needs much more vitamin B6 or not. The NAT2 gene is important in inactivating the INH-TB treatment. We think half the general population are "slow metabolizers or inactivators" as a result of their NAT2 gene arrangement and that this may affect the individual's need for vitamin B6. "Slow INH inactivators" may need more B6 than NAT2 "fast inactivators"

It is important to realise that not everyone on HAART/ARVs will develop peripheral neuropathy, but some individuals are at risk of developing this side effect. It will be useful to identify who are at-risk so that we can try and prevent this complication from developing. 


\section{WHAT WILL HAPPEN IF I AGREE TO PARTICIPATE?}

We will ask you not to eat or drink anything from 10pm the night before your appointment. At your appointment you will be asked to complete a questionnaire and give some basic medical information about yourself. Following this the doctor will examine you (looking specifically for changes in your body and any damage to the nerves in your feet) and will then insert a drip cannula- this is a small plastic device that stays inside the vein for 2 hours allowing all further blood samples to be taken from it without any further need for needle pricks. Blood will then be drawn into a syringe ( $25 \mathrm{ml}, 1$ tablespoon) from the cannula. After taking the blood sample, you will be asked to drink a glass of water with glucose, a form of sugar. Further blood samples will be taken $30 \mathrm{~min}$ and $120 \mathrm{~min}$ after taking this sugar drink. The blood will be sent to a laboratory and tested for glucose, insulin, cholesterol, and lactate. Some of the blood will be frozen and kept for testing at a later stage such as the B6 levels. You will be asked to sign this form to allow us to take some blood for specific gene testing such as the NAT2 test; you can either agree to the NAT2 test alone or agree that we may store the blood for later genetic testing if we get given permission from the University of Cape Town ethics committee to do such a test. Stored blood and genetic samples will not be labeled with your personal information.

Whilst waiting for your blood samples to be taken, the study staff will do the following: a) using a tape measure they will measure certain areas of your body including your waist, your hips, your height, your upper arm and your thigh, b) take blood pressure measurements c) measure your body weight using a scale. After the blood is taken or at another appointment, special X-rays will be organized, called DEXA and CT scans. These scans are done to examine the amount of fat in various areas of your body. Each test takes less than 30 minutes to complete. After your blood tests you will be given some lunch.

We would then like to follow your progress on HAART over the $1^{\text {st }}$ year of treatment and document if you develop any problems or not. It is very important to see everyone at regular intervals- whether you have developed problems or not. All transport to and from the study clinic at Groote Schuur Hospital will be paid by the study. You will also be given R150 after each study visit to compensate you for the day spent at the study clinic. To make it more pleasant for you on the clinic day we will also provide a movie to be watched in the clinic lounge area.

The study staff will also review all of your previous clinic records including all of your previous blood test results (including HIV status, viral load, CD4 count, liver function, kidney function, etc.

WHAT ARE THE POSSIBLE DISCOMFORTS OF PARTICIPATING IN THE STUDY? Having blood taken will be the only discomfort in this study. Risk of infection will be minimized by using sterile procedures, and all blood samples will be taken by a qualified study nurse or doctor.

\section{WHAT ARE THE POSSIBLE BENEFITS?}

If you are found to have any of the above-mentioned side effects of HAART, then arrangements will be made for you to be seen at a hospital where doctors specially trained in looking after these problems will look after you. This study will help doctors find these problems early, therefore the required investigation and treatment can be done before any further problems arise. 
DO I HAVE TO PARTICIPATE?

You do not have to participate in this study. Your participation is voluntary and if you agree to participate then you will be required to sign a form. You can withdraw from the study at any time and this will in no way affect your treatment in the future.

WILL THE INFORMATION REMAIN CONFIDENTIAL

Your records will only be viewed by your doctors and people involved in this study, including research oversight agencies, which support the rights of subjects involved in research (such as ethics committees or the Office of Human Research Protections). Your details will not be made available to anybody not involved in this study. Although absolute confidentiality cannot be guaranteed, the staff involved in this study will strive to keep your records as confidential as possible. All the staff have to sign a confidentiality agreement.

CONTACT DETAILS OF STUDY STAFF

Should you have any questions, then please contact the study doctor Dr C Centner or leave a message at UCT neurology 021-404-3198. The UCT Human Research Ethics Committee may be contacted at 021-406-6338. 
UCT ICD modified Dec 09

\section{Written Informed Consent for the Patient}

Study Number:

Patient Initials:

\section{(Name of patient in block letters)}

Have read and understood all the information given to me about my participation in this study and I have been given the opportunity to discuss it and ask questions. I voluntarily agree to take part in this study and have received an information sheet outlining the details of this study. I understand that I am able to withdraw from this study at any time.

Please circle if you are willing to give a $20 \mathrm{mls}$ (4 teaspoons) of your blood for storage to be used by this study and /or at a later date; any further research studies must and will always first be cleared by the UCT research ethics committee before the researchers can use your blood.

- I am willing to allow a blood specimen to be stored so that we may measure vitamin B6 levels at a later stage:

YES NO.

- I am willing to allow a blood specimen for DNA extraction to determine my NAT2 gene status:

YES NO.

- I am willing to allow the left-over DNA to be used for possible future genetic studies IF the research project has been cleared by the UCT research ethics committee before the researchers can use my specimen

YES NO.

- I am willing to allow the left-over blood to be used for possible future studies IF the research project has been cleared by the UCT research ethics committee before the researchers can use my specimen

YES NO

Signature of patient

Date

Printed Name of Patient

I have explained the nature and purpose of the study to the patient named above.

Signature of doctor

Print Name of Doctor

Date 
13) Ethics approval 


\section{July 2017}

HREC REF: 221/2008

Prof Jeanine Heckmann

Neurology

E8-74, NGSH

\section{Dear Prof Heckmann}

\section{PROJECT TITLE PREVALENCE OF HIV NEUROPATHY AND RISK FACTORS FOR ANTIRETROVIRAL TOXIC NEUROPATHY IN AN HIV POSTIIVE COHORT OF BLACK SOUTH AFRICANS (MMED CANDIDATE - DR C CENTNER)}

Thank you for submitting your request to the Faculty of Health Sclences Human Research Ethlcs Commlttee.

The HREC acknowledge that the MMed candldate Dr Chad Centner will also be Involved In this study.

Please quote the HREC reference number In all your correspondence.

Yours sincerely 
14) Instructions to authors (Muscle \& Nerve) 
Muscle Nerve 00: 00-00, 2017

(c) 2017 Wiley Periodicals, Inc.

Published online May 2017 in Wiley Online Library (wileyonlinelibrary.com). DOI 10.1002/mus.0000

\section{ANEEM MUSCLE ${ }^{2}$ NERVE INSTRUCTIONS for AUTHORS}

The Journal is composed of 9 sections

\begin{tabular}{|c|c|c|c|c|c|}
\hline Manuscript Type & Abstract & Figures/Tables & Key Words & Word Count /References & Description \\
\hline $\begin{array}{l}\text { Clinical Research } \\
\text { Articles }\end{array}$ & $\begin{array}{l}\text { (150 words) Structured } \\
\text { headings: } \\
\text { Introduction, Methods, } \\
\text { Results, Discussion }\end{array}$ & $\begin{array}{l}\text { Maximum of } 8 \\
\text { figures or tables. } \\
\text { Additional ones } \\
\text { must be submitted } \\
\text { as on-line } \\
\text { supplementary } \\
\text { material }\end{array}$ & $\begin{array}{l}5 \text { key words on } \\
\text { the abstract } \\
\text { page pertaining } \\
\text { to all major } \\
\text { points of the } \\
\text { contribution }\end{array}$ & $\begin{array}{l}\text { Maximum length } \\
4000 \text { words No } \\
\text { limit on references, } \\
\text { but authors are } \\
\text { asked to focus on } \\
\text { the most important } \\
\text { ones of highest } \\
\text { relevance }\end{array}$ & $\begin{array}{l}\text { Original clinical research } \\
\text { relevant to human } \\
\text { neuromuscular disease. }\end{array}$ \\
\hline Short Reports & $\begin{array}{l}\text { (150 words) Structured } \\
\text { headings: } \\
\text { Introduction, Methods, } \\
\text { Results, Discussion }\end{array}$ & $\begin{array}{l}\text { Maximum of } 3 \\
\text { tables or figures. } \\
\text { Additional ones } \\
\text { must be submitted } \\
\text { as on-line } \\
\text { supplementary } \\
\text { material }\end{array}$ & $\begin{array}{l}5 \text { key words on } \\
\text { the abstract } \\
\text { page pertaining } \\
\text { to all major } \\
\text { points of the } \\
\text { contribution }\end{array}$ & $\begin{array}{l}\text { Maximum length } \\
1500 \text { words. } \\
\text { Maximum of } 30 \\
\text { references. }\end{array}$ & $\begin{array}{l}\text { Preliminary } \\
\text { communications, pilot } \\
\text { studies, reports of small } \\
\text { patient series, and } \\
\text { research studies with } \\
\text { limited data. Case } \\
\text { reports are not to be } \\
\text { presented in this } \\
\text { format, but as } \\
\text { Noteworthy Cases }\end{array}$ \\
\hline $\begin{array}{l}\text { Invited Review } \\
\text { Articles }\end{array}$ & $\begin{array}{l}\text { (150 words) Non- } \\
\text { Structured }\end{array}$ & $\begin{array}{l}\text { Maximum of } 8 \\
\text { figures or tables. } \\
\text { Additional ones } \\
\text { must be submitted } \\
\text { as on-line } \\
\text { supplementary } \\
\text { material }\end{array}$ & $\begin{array}{l}5 \text { key words on } \\
\text { the abstract } \\
\text { page pertaining } \\
\text { to all major } \\
\text { points of the } \\
\text { contribution }\end{array}$ & $\begin{array}{l}\text { Maximum length } \\
6,000 \text { words. No } \\
\text { limit on references, } \\
\text { but authors are } \\
\text { asked to focus on } \\
\text { the most important } \\
\text { ones of highest } \\
\text { relevance. }\end{array}$ & $\begin{array}{l}\text { Review of current } \\
\text { topics of importance, } \\
\text { usually solicited by the } \\
\text { Editor. }\end{array}$ \\
\hline $\begin{array}{l}\text { Issues \& } \\
\text { Opinions }\end{array}$ & $\begin{array}{l}\text { (150 words) Non- } \\
\text { Structured }\end{array}$ & $\begin{array}{l}\text { Maximum of } 4 \\
\text { figures or tables. } \\
\text { Additional ones } \\
\text { must be submitted } \\
\text { as online } \\
\text { supplementary } \\
\text { material }\end{array}$ & $\begin{array}{l}5 \text { key words } \\
\text { on the abstract } \\
\text { page pertaining } \\
\text { to all major points } \\
\text { of the contribution }\end{array}$ & $\begin{array}{l}\text { Maximum length } \\
2,000 \text { words. } \\
\text { Maximum of } 30 \\
\text { references. }\end{array}$ & $\begin{array}{l}\text { Current topics in } \\
\text { neuromuscular } \\
\text { disease. Need not be } \\
\text { data-based. Novel } \\
\text { hypothesis and } \\
\text { discussion of } \\
\text { controversial topics will } \\
\text { be considered. }\end{array}$ \\
\hline $\begin{array}{l}\text { Noteworthy Cases } \\
\text { (Published on-line } \\
\text { only) }\end{array}$ & None & $\begin{array}{l}\text { Maximum of } 2 \\
\text { tables or figures. }\end{array}$ & $\begin{array}{l}5 \text { key words } \\
\text { pertaining to all } \\
\text { major points of } \\
\text { the contribution }\end{array}$ & $\begin{array}{l}\text { Maximum length } \\
1,000 \text { words. } \\
\text { Maximum of } 15 \\
\text { references. }\end{array}$ & $\begin{array}{l}\text { Reports of cases or } \\
\text { families with rare, } \\
\text { illustrative } \\
\text { neuromuscular } \\
\text { diseases }\end{array}$ \\
\hline $\begin{array}{l}\text { Letters to the } \\
\text { Editor } \\
\text { (Published on-line } \\
\text { only) }\end{array}$ & None & $\begin{array}{l}\text { Maximum of } 1 \\
\text { figure or table }\end{array}$ & None & $\begin{array}{l}\text { Maximum length } \\
500 \text { words. } \\
\text { Maximum of } 5 \\
\text { references. }\end{array}$ & $\begin{array}{l}\text { Comment on papers } \\
\text { published in this journal } \\
\text { or other relevant } \\
\text { matters }\end{array}$ \\
\hline
\end{tabular}




\section{INSTRUCTIONS FOR AUTHORS}

\section{STYLE}

Sources. Webster's Third New International or New Collegiate dictionaries (G. \& C. Merriam Co., Springfield, MA) should be used for spelling and hyphenation of nonmedical terms, and Dorland's Illustrated Medical Dictionary (WB Saunders, Philadelphia) for medical terms. Good sources for general style (grammar, punctuation, capitalization, etc.) are: A Manual of Style (The University of Chicago Press, Chicago) and The Elements of Style, by Strunk and White (Macmillan Publishing Co., New York). For units of measure, symbols and nomenclature for biochemistry and biology use the $C B E$ Style Manual (American Institute of Biological Sciences, Arlington, VA) and for medicine, use the AMA Stylebook and Editorial Manual (American Medical Association, Chicago).Standard United States spellings will be used in all publications.

Numbers. Use numerals for all units of measure and time, and for all enumerations (e.g., $3 \mathrm{~mm}, 55 \%$, 2 hours, 9 months, 20 years, 1 of 19 patients). SI unit conversions should appear in parentheses following all units of measure. Spell out numbers beginning a sentence.

Abbreviations. Abbreviations should be kept to a minimum, because their use often confuses readers who are not familiar with the subject matter. Only standard abbreviations, as listed in the $C B E$ Style Manual and the AMA Stylebook and Editorial Manual (see above), may be used without definition. Terms appearing frequently within a paper may be abbreviated, but should be spelled out at first citation, with the abbreviation in parentheses. The term "MRI" for magnetic resonance image is an exception and need not be spelled out at first citation.

\section{MANUSCRIPT PREPARATION}

- Word format preferred

- Electronic versions in ASCII or PDF are not acceptable

- Double Space entire manuscript, including reference section

- Organize manuscript in the following order, with each component beginning on a separate page and with a running title and page number in the upper right hand corner of each page

\section{Title page (page 1)}

- Article Title (80 spaces Maximum)

- Authors' full name (first name, middle initial, surname) and graduate degree (no more than 2)

- Author Affiliations (name of department if any, institution, city and state or country where work was done) **Authors with multiple affiliations should provide only their primary affiliation.

- Acknowledgments if applicable (grant support and individuals who were of direct help in preparation of the study

- Number of words in abstract

- Number of words in manuscript (excluding abstract, references, table titles, and figure legends).

- Name/address and email address of the author to whom reprint requests are to be sent

- Running title (30 spaces Maximum)

- If part or all of the material is contained within a presentation made at a national meeting, the organization, city, and date of the presentation should be included as a footnote, but details of any abstracts should not be cited here.

\section{Ethical Publication Statement}

- All papers must include the following statement to indicate that the authors have read the Journal's Position on Issues Involved in Ethical Publication and affirm that their report is consistent with those guidelines: "We confirm that we have read the Journal's position on issues involved in ethical publication and affirm that this report is consistent with those guidelines."

\section{Disclosure of Conflicts of Interest}

- One of the following sentences must be included: either "Author A has received support from, and/or has served as a paid consultant for .... Author B has received support from.... The remaining authors have no conflicts of interest." Or "None of the authors has any conflict of interest to disclose." Note: Disclosure is needed for financial income/ payment from commercial sources, the interests of which are relevant to this research activity. Please identify sources from which financial assistance/income was obtained during the period of the research activity and generation of the current report. Grants from government and/or private agencies should be identified in the Acknowledgements section. For additional details see Muscle and Nerve's Position on Issues Involved in Ethical Publication below.

\section{Abstract (page 2)}

- Include title of article

- No more than 150 words

- Depending on type of article, the abstract should include sections labeled: 


\section{INSTRUCTIONS FOR AUTHORS}

Introduction, Methods, Results, Discussion. For basic research publications a statement of clinical relevance is encouraged. Authors who wish to have additional information about the structured abstract format are referred to the National Library of Medicine website: (http://www.nlm.nih.gov/bsd/policy/structured_abstracts.html) and to an article that reviews the subject: (Harbourt AM, Knecht LS, Humphreys BL. Structured abstracts in MEDLINE, 1989-1991. Bull Med Libr Assoc. 1995;83:190-195).

\section{Key Words}

- The authors should provide 5 key words on the bottom of the abstract page pertaining to all major points of their contribution. This will help index the article for reference citations. Authors are suggested to refer the below link for adding key words: Search Engine Optimization: For Authors

\section{Text (starts on page 3 )}

- Organized in the following format; Introduction, Methods, Results, and Discussion. Other descriptive headings and subheadings may be used if appropriate. Every effort should be made to avoid jargon, to spell out all nonstandard abbreviations the first time they are mentioned, and to present the contents of the study as clearly and as concisely as possible.

- The methods, apparatus (including manufacturer's name and address), and procedures should be identified in sufficient detail to allow other investigators to reproduce the results. References should be given for all discussions of previous studies and for all nonstandard methods used. For experiments in which humans or animals were studied, see Muscle and Nerve's Position on Issues Involved in Ethical Publication below. For drugs and chemicals, the generic name should be used. Patients' names, initials, or hospital numbers should not be used.

- Be sure that all references and all tables and figures are cited within the text. The tables and figures should be numbered according to the order in which they appear. Data appearing in tables or figures should be summarized, not duplicated, in the text. All data cited in the text should be checked carefully against the corresponding data in the tables to ensure that they correspond, and all names cited in the text should be checked carefully against the references to ensure that the spelling is correct. Any ambiguous symbols (e.g., the letter "O" versus the numeral " 0 ," the letter "I" versus the numeral "1") should be identified. Tables should be of a size that can be printed in a vertical format on the page, thus the width should be no more than 6 inches.

\section{Abbreviations}

- All abbreviations used in the text should be listed and defined in alphabetical order on a separate page. This list should appear just before the references

\section{References}

- Double-spaced

- Listed and numbered in the order of citation and number them accordingly.

- Identify references in the text, tables, and legs by Arabic numerals typed as superscripts.

- Include ALL author names (surnames followed by initials, use "et al" after the sixth author in the case of multi-authored works),

- Include the title of the article with the same spellings and accent marks as in the original

- Include the journal title abbreviated as it appears in the Index Medicus or spelled out if it is not listed there

- Include the date of publication

- Include the volume number

- Include inclusive page numbers.

- For books be sure to include the chapter title, chapter authors, editors of the book, title of the book (including volume or edition number), publisher's name and location, date of publication, and appropriate page numbers.

- Unpublished observations," "personal communications," and information that has been obtained from manuscripts "submitted for publication" but not yet accepted should not appear in the references but should be cited in parentheses in the text. Unpublished observations should include the authors, the year, and should be accompanied by letters of permission from all individuals cited; quotations from manuscripts that have been submitted for publication should include the authors, the title of the manuscript, and the date. Manuscripts that have been accepted for publication but have not yet been published may appear in the references. Include the authors, manuscript title, and name of journal, followed by "to be published" in parentheses. 


\section{INSTRUCTIONS FOR AUTHORS}

Examples of the correct format are as follows:

\begin{tabular}{ll}
\hline Article Type & \multicolumn{1}{c}{ Example } \\
\hline Journal Article & Franssen H, Straver DC. Pathophysiology of immune-mediated demyelinating neuropathies- \\
& Part II: neurology. Muscle Nerve 2014;17:4-20. \\
Journal Article & Dispenzieri A, Kyle RA, Lacy MQ, Rajkumar SV, Therneau TM, Larson DR, et al. POEMS \\
(use et al after $6^{\text {th }}$ author) & syndrome: definitions and long-term outcome. Blood 2003; 101:2496-2506. \\
URL & Pedersen J, Wallace M. 1999. Wiley Journals DTD: Guidelines for reference tagging. \\
& Available at http://jws-edcd. wiley.com:8255/refguide.html. Accessed February 4, 2002. \\
DoI & Oussalah M. Some notes on fusion of uncertain information. International Journal of Intelligent \\
& Systems 1984;19(6). Published online: April 23, 2004. DOI: 10.1002/int.20001. \\
Book & Smith, J.A. 2001. How to Write Journal Guidelines. Springer: New York \\
Chapter in a book & Katz JN. Developments in surgery for rheumatic and musculoskeletal disorders. In: Pisetsky \\
& DS, editor. The ACR at 75: a diamond jubilee. Hoboken (NJ): Wiley-Blackwell; 2009. p. 87-91.
\end{tabular}

\section{Tables}

- Double-spaced

- Separate pages

- Word file, NOT photograph or image files

- If table must exceed 1 typewritten page, duplicate headings on the second sheet

- Numbered in the order in which they are cited in the text

- Include a title at top of table

- Every column (including the left-hand (stub) column should have a heading

- Define all abbreviations immediately below the table

- Indicate the units of measurements for all values

- Use commas for all numbers exceeding 999, and use zeros before decimals for numbers less than 1

- Organized so that like data are read vertically, not horizontally.

- Do not use internal horizontal or vertical lines to separate sections

- Explain all empty spaces or dashes

- Indicate footnotes to the table using the following symbols

- * (asterisk), $\dagger$ (dagger), $\ddagger$ (double dagger), § (section mark), (parallels), (paragraph mark), \# (number sign).

- Letters of the alphabet, lower case and italic, should be used instead if there are more than 7 footnotes.

- Symbols (or letters) should appear after commas and periods, before colons and semicolons, and should be superscript.

- If data from any other source, published or unpublished, are used, obtain permission for their use and cite the source in the legend.

\section{Figure/Images}

- JPEG, TIFF or EPS file format (Tagged Image File, Encapsulated PostScript)
- Each file must include all subparts (A, B, C, etc.) to the figure. Subparts should not be uploaded individually

- Resolution

- Halftones are to be scanned at 300 dots per inch (dpi)

- Line Art is to be scanned at $1200 \mathrm{dpi}$

- Figures prepared in Word, Excel, Microsoft Publisher, Lotus 123, PowerPoint and Corel Draw are not acceptable as digital files

- If your files have been prepared in one of these formats and cannot be converted you will be required to mail high quality hard copy figures.

- All images must be saved and submitted in final size. The final figure sizes are: 1 column $=3$-in.$\quad(8.25-\mathrm{cm}) \quad$ wide,$\quad 1.5$ column $=5$-in. $(13-\mathrm{cm})$ wide, 2 columns $=6$ in. $(17.15-\mathrm{cm})$ wide. Figures should not exceed 8-in. (21.6-cm) in height. All cropping and manipulation must be completed before the images are submitted to the publisher.

- Avoid use of fine lines (point and below) for graphs and charts

- Use only Adobe Type 1 fonts in creating images, and limit the number for fonts used

- Do not reletter images in Photoshop. If relettering must be done, import the image into either Freehand or QuarkXPress and reletter, then make an EPS file.

- Make sure all scanned images are "clean." Look for and clean up dust specks, scratches, tape marks, and anything that is not part of the actual image. Files generated in Freehand should be saved in EPS format.

- Photomicrographs must include a calibration bar of appropriate length (e.g., $1 \mu \mathrm{m}$, $0.1 \mathrm{~mm}$, etc.) Symbols used in micrographs should contrast with the background.

- For photographs of persons, written permission from the subject must be supplied. 


\section{INSTRUCTIONS FOR AUTHORS}

Unless specified otherwise, the subject's eyes will be masked to prevent identification.

- Digital Figures. To ensure that your digital graphics are suitable for print purposes, please go to RapidInspector ${ }^{\mathrm{TM}}$ at http:/ / rapidinspector.cadmus.com/wi/index.jsp . This free, stand-alone software application will help you to inspect and verify illustrations right on your computer.

\section{Figure Legends}

- Less than 200 words

- Double spaced

- Numbered with Arabic numerals corresponding to the illustrations.

- When symbols, arrows, numbers, or letters are used to identify parts of the illustration, each should be explained clearly in the legend

- For photomicrographs, the internal scale markers should be defined and the methods of staining should be given. If the figure has been previously published a credit line should be included

\section{COLOR POLICY:}

Figures will be published in color online at no charge. Authors are required to pay the cost of reproducing color figures in print. Muscle $\mathcal{E}$ Nerve charges per figure, $\$ 600$ for the first figure. Second, third and fourth figures are billed at $\$ 400$ each.

\section{DATA ACCESS}

For reports of original data, at least 1 author (e.g., the corresponding or principal investigator) is expected to have full access to all the data in the study and to take responsibility for its accuracy. Readers are referred to the editorial by Rosenberg et al. (Muscle Nerve 2002;25:133-134). Such access must be confirmed on the Author Responsibility section of the submission site.

\section{Muscle $\mathcal{E}$ 'Nerve's Position on Issues Involved in Ethical Publication}

\section{(1) Authorship/Credit}

Muscle $\mathcal{E}$ Nerve follows the guidelines of the International Committee of Medical Journal Editors regarding criteria for authorship (http://www.icmje.org/). The author list should include those who have made substantial intellectual/conceptual contributions to the work. Such contributions should include participation in: (a) substantial contributions to conception and design, acquisition of data, or analysis and interpretation of data; (b) drafting the article or revising it critically for important intellectual content; c) final approval of the manuscript version to be published, and (d) agreement to be accountable for all aspects of the work. We strongly discourage the inclusion of "honorary" authors (individuals who are listed as authors but have not contributed to the work/manuscript - e.g., heads of departments) and "ghost" authorship (individuals who have substantively contributed to the work and/or manuscript but are not listed as authors or contributors). In cases where writing support is necessary, the writer(s) should be acknowledged in the Acknowledgements section, and the source of funding for writing support should be provided under Disclosure of Conflicts of Interest. The corresponding/ submitting author must, when submitting a manuscript, give assurance that all authors have read and approved the submitted manuscript. The corresponding/ submitting author should also give assurance that all authors have seen and approved the final (accepted) manuscript, and that the manuscript includes all conflict of interest declarations. All individuals who have contributed to the work but do not meet criteria for authorship should be cited in the Acknowledgement section.

\section{(2) Funding}

Sources of funding (for the research, data analysis, and manuscript generation) should always be disclosed in the Acknowledgements section. Sources may include government funding agencies, institutions and departments, private industry, and charitable organizations and foundations. Funding for all authors should be acknowledged.

\section{(3) Procedures involving Human and Animal} Subjects

The authors should include within the manuscript an explicit statement indicating that the submitted study was approved by the relevant research ethics committee or institutional review board (IRB), and that informed consent was obtained from research subjects. When the study involves human participants (including material from human subjects), authors should also provide assurance that appropriate consent was obtained. When studies involve animal subjects, authors should provide methodological details about steps taken to minimize pain/discomfort. Such papers must contain a statement that affirms that the experimental protocols were approved by the institutional animal care and use committee (IACUC).

\section{(4) Confidentiality}

In all cases, information and images derived from individual patients must be presented with assurance of appropriate consent and with details removed that might reveal identity of the individual.

\section{(5) Disclosure}

All authors are required to disclose associations which might affect their ability to present and/ or 


\section{INSTRUCTIONS FOR AUTHORS}

interpret data objectively, particularly financial ties to funding sources for the work under review (e.g., membership on corporate scientific boards, stock ownership, consultant arrangements, patent ownership or application, etc.). Disclosure of such associations for the Editorial personnel of Muscle $\mathcal{E}^{\circ}$ Nerve (Editors-in-Chief, Associate Editors, Editorial Board members) will be published each year. Reviewers will also be asked to affirm that they have no conflict of interest when critiquing a manuscript.

\section{(6) Research Misconduct (Data Fabrication/} Falsification)

Muscle $\mathcal{E}$ Nerve will attempt to ensure that any allegations of misconduct are properly investigated. In the case of any allegations, authors will be given a right to respond. While the Journal is limited in its ability to investigate misconduct, we will seek COPEs (Committee on Publication Ethics) advice and alert appropriate bodies and encourage them to investigate.

\section{(7) Plagiarism, Duplication, and Redundant Publication}

Muscle $\mathcal{E}$ Nerve requires that work submitted for publication is the authors' own work and has not been misappropriated. When previously published material is used, appropriate credit must be given and written permission obtained (for use of copyrighted material). Muscle E N Nerve also explicitly discourages duplication of published material and redundant publication. All manuscripts submitted to Muscle E Nerve are checked with the iThenticate ${ }^{\circledR}$ software to detect instances of overlapping and similar text. In the case of apparent or substantial overlap, authors will be asked to rewrite their article.

\section{(8) Corrections of Erroneous Information}

Authors are expected to proof-read their articles carefully before returning page proofs for publication. They should make needed corrections at this time. We recognize that it is only human to err occasionally, and the Journal is committed to correcting mistakes when those errors affect the interpretation of data or information presented in an article. Such corrections will be published in the form of an Erratum, and linked to the original article electronically. Errors that result from author oversight in the proofing process, and that do not affect data interpretation, will not be corrected.

\section{(9) Peer Review}

Muscle $\mathcal{E}$ Nerve is committed to a peer-review system that is fair to the author and enhances the value of the articles published in the Journal. In order to encourage qualified reviewers to offer their time and efforts to the Journal, reviewer identity is kept confidential. Reviewers are chosen for their expertise in the field; conflicts of interest are avoided whenever the Editors are aware of such issues, and reviewers are asked to affirm that they have no conflicts of interest in reviewing a given Muscle $\mathcal{E}$ Nerve manuscript. Authors are encouraged to identify specific individuals who, they believe, cannot provide unbiased review.

\section{REVIEW AND PRODUCTION PROCESS}

Manuscripts are evaluated by the editor and at least 2 reviewers, who are informed of the confidential nature of the review process. Decisions of the editor are final and rejected manuscripts will not be considered further. All material accepted for publication is subject to copy editing. Authors will receive page proofs of their article before publication, and should answer all queries and carefully check all editorial changes at this stage. Authors are asked to check for misprints or syntactic errors and not to otherwise revise the manuscript. The current policy of Muscle $\mathcal{E}$ Nerve calls for an editorial review of all notes added in proof but not minor modifications made in the text. Any major alteration that would substantially delay publication must be approved by the editor, in consultation with the reviewers, if necessary. Authors are responsible for the scientific content of their article.

\section{Accepted Articles}

Once a paper is accepted, all files in the final version of the manuscript will be placed in the Accepted Articles section of the journal website. The manuscript files will be in a pdf format. Each article will include a digital object identifier (DOI) and a collaborative reference linking service through which readers can click on a reference citation and immediately access article content. Once articles are published electronically, it is not possible for authors to make further changes before the print version appears. The print version will indicate the on-line publication date. This makes articles available before the print version and reduces publication time to a few days.

\section{Referrals to the Journal "Brain and Behavior"}

This journal works together with Wiley's Open Access Journal, Brain and Behavior, to enable rapid publication of good quality research that is unable to be accepted for publication by our journal. Authors will be offered the option of having the paper, along with any related peer reviews, automatically transferred for consideration by the Editor of Brain and Behavior. Authors will not need to reformat or rewrite their manuscript at this stage, and publication decisions will be made a short time after the transfer takes place. The 


\section{INSTRUCTIONS FOR AUTHORS}

Editor of Brain and Behavior will accept submissions that report well-conducted research which reaches the standard acceptable for publication. Accepted papers can be published rapidly: typically within 15 days of acceptance. Brain and Behavior is a Wiley Open Access journal, and article publication fees apply. For more information please go to Brain and Behavior.

\section{EarlyView}

Once a corrected proof is received by the publisher from the author and reviewed with the Editor, individual articles are published on-line in the EarlyView service maintained by the publisher. Articles are available as PDF full-text and HTML full-text.

\section{Wiley: Permissions and Reprints}

You can now obtain permission to reproduce or make copies of Wiley content, for commercial or non-commercial re-use, directly from the point of content on Wiley's websites. For additional information, please visit http://www.wiley.com/ WileyCDA/Section/id-403426.html

\section{Wiley Online Library}

For additional tools visit Author Resources (http://authorservices.wiley.com/bauthor/default. asp) - an enhanced suite of online tools for Wiley journal authors, featuring Article Tracking, E-mail Publication Alerts and Customized Research Tools. 